\title{
Analysis of Thermo-Hydro-Mechanical Coupling of Coal and Gas with Absorption/Desorption Thermal Effect
}

\author{
Jianfeng Hao $\mathbb{D}^{1},{ }^{1}$ Bing Liang $\mathbb{D}^{2},{ }^{2}$ and Weiji Sun $\mathbb{D}^{2}$ \\ ${ }^{1}$ College of Mining, Liaoning Technical University, Fuxin, Liaoning 123000, China \\ ${ }^{2}$ School of Mechanics and Engineering, Liaoning Technical University, Fuxin, Liaoning 123000, China \\ Correspondence should be addressed to Jianfeng Hao; 471610041@stu.lntu.edu.cn
}

Received 2 November 2020; Revised 20 November 2020; Accepted 28 November 2020; Published 23 December 2020

Academic Editor: Yuantian Sun

Copyright (C) 2020 Jianfeng Hao et al. This is an open access article distributed under the Creative Commons Attribution License, which permits unrestricted use, distribution, and reproduction in any medium, provided the original work is properly cited.

Coal adsorption/desorption gas can cause temperature changes. Moreover, the pressure difference between the high gas pressure area and the low gas pressure area in the coal may affect the coal adsorption/desorption gas thermal effect. To study the effect of adsorption/desorption thermal effect on the evolution law of coal and gas outburst precursor information under different pressure differences, the adsorption/desorption thermal effect experiments were carried out. And the thermo-hydro-mechanical coupling model was established, which reflects the interaction between coal and gas. Under the action of ground stress, pore pressure, adsorption expansion stress, and thermal expansion stress, the model includes the dynamic evolution of coal porosity and permeability, gas adsorption-desorption-diffusion-seepage, and energy accumulation and dissipation. Using the coupling model, the mechanism of adsorption/desorption thermal effect on the evolution of outburst precursor information and the mutual coupling relation between coal and gas is analyzed. The experimental results show that the relation between pressure difference and coal sample temperature variation is linear, and the pressure difference has a quadratic parabolic relation with the temperature accumulation of coal sample. As the pressure difference increases, the temperature variation of the coal sample gradually increases, but the temperature accumulation gradually decreases. Numerical simulation results show that as the pressure difference increases, the changes in coal temperature and gas pressure gradually decrease, and the thermal expansion strain caused by the adsorption/desorption thermal effect decreases, and the permeability increases. Comparing the calculation results with or without the adsorption/desorption thermal effect, the volumetric strain, temperature, and permeability of the coal have significant changes when the adsorption/desorption thermal effect is considered, and the gas drainage volume increases as the pressure difference increases. The effect of thermal expansion strain caused by adsorption/desorption thermal effect on gas seepage is greater than the effect of temperature change on gas seepage.

\section{Introduction}

Coal and gas outburst is a complex dynamic disaster in the process of coal mining. In recent years, most of the major safety accidents in China's coal mines are caused by the abnormal gas outflow and the coal and gas outburst. Coal and gas outburst has always been a serious threat to coal mine safety production and has become a major issue that needs to be solved urgently in coal mining [1-5]. As the mining depth increases, the in situ stress, temperature, and gas pressure of the coal seam increase and the permeability decreases. The interaction mechanism of coal and gas under the coupling action of stress field, seepage field, and temperature field is more complicated, and the temperature field has become an important research target [6-9]. Meanwhile, the pressure difference between the high gas pressure area in front of the working face and the low gas pressure area near the coal wall is an important parameter to control the outburst strength of coal and gas. Moreover, the adsorption/desorption thermal effect may be different under different pressure differences [10-13].

To study the characteristics of coal adsorption/desorption gas thermal effect, the influence of adsorption/desorption thermal effect on the interaction of coal and gas, and the evolution law and mutual coupling relation of coal and gas outburst precursor information under multifield coupling, 
scholars have carried out a lot of research work and established multifield coupling model suitable for a variety of complex situations [14-17]. Coal releases heat during the process of gas adsorption and absorbs heat during the process of gas desorption [18-20]. Jacek [21] gave a calculation method of the maximum volume of work which can be performed by a gas while being liberated from a coal bed. Rahman [22, 23] reported the theoretical frameworks for the thermodynamic quantities for the adsorption of methane onto various carbonaceous materials. Temperature variation causes deformation, and deformation generates heat, which causes temperature variation. Liu [24] proposed the thermal deformation effect of adsorption-desorption on the basis of the molecular migration and energy conversion during the adsorption-desorption. At present, multifield coupling is a hot research target [25-28]; the fields of coalbed methane extraction, shale gas extraction, coal and gas outburst prevention, and nuclear waste treatment all involve thermohydro-mechanical coupling issues [29, 30]. Thararoop [31] believed that existing coal bed methane (CBM) simulators usually treat the coal seam as a dual pore and single permeability system, ignoring the influence of water in the coal matrix. The model includes the influence of moisture in the coal matrix and the shrinkage and expansion of coal. Considering the competitive effects of thermal expansion, nonisothermal gas adsorption, and thermal fracturing, Teng [32] established a fully coupled thermo-hydro-mechanical model of coal deformation, gas flow, and heat transfer. Zhu [33] uses the finite element method to establish and solve a fully coupled model of coal deformation, gas transport, and heat transport. A general model was established to describe the evolution of coal porosity under the combined influence of gas pressure, thermally induced solid deformation, thermally induced gas adsorption changes, and solid deformation caused by gas desorption. Zhou [34] proposed a coupled thermal pore elastic model, which considers the compressibility and thermal expansion of the convective heat flow of the components, as well as the changes in the porosity and related characteristics of the saturated soil. The model also considers the thermodynamically coupled water and heat flow. Fall [35] gave a detailed formula for coupling moisture and gas transmission in deformable porous media is given. This model takes into account the fluid flow under damage control and the coupling of hydraulic and mechanical processes. The model also considers the coupling of diffusion coefficient and mechanical deformation and considers the changes in capillary pressure caused by changes in permeability and porosity. To analyze the influence of gas desorption on gas outburst, An [36] established a mechanical process model in the process of gas migration and tunneling. The study understands the influence of absorption shrinkage and mechanical changes on the protrusion. Tao [37] carried out physical simulation experiments on coal and gas outbursts and established a thermo-hydro-mechanical coupling model of gassy coal.

In summary, the existing research did not use experiments to analyze the influence of coal adsorption/desorption gas thermal effect on the evolution law of outburst precursor information. In addition, there are few quantitative studies on the influence of adsorption/desorption thermal effect on the interaction between coal and gas. Using the self-designed coal and gas thermo-hydro-mechanical coupling experiment system and the cyclic-step adsorption/desorption experiment method, the temperature change of coal adsorption and desorption gas under different pressure differences was discussed. Based on the experimental results, a thermohydro-mechanical coupling model of gassy coal with the adsorption/desorption thermal effect was established, and the model is solved by COMSOL Multiphysics. Comparing the calculation results with or without the adsorption/desorption thermal effect, the effect of the adsorption/desorption thermal effect on the evolution law of precursor information and the effect of it on the mutual coupling relation between coal and gas were studied.

\section{Materials and Methods}

2.1. Experimental System. To study the temperature evolution law of coal adsorption/desorption gas under different pressure differences, an experiment system of coal adsorption and desorption gas was designed. The device used in this experiment is to add a thermostat and a standard tank to the original device. The experimental device is shown in Figure 1.

2.2. Coal Samples and Experimental Methods. The coal sample used in the experiment was taken from the Xinjiang Coal Mine of Yangquan Coal Group, which belongs to a high gas outburst mine. The $3 \#$ coal seam is the outburst coal seam. Obtain coal sample with the size of $40 \mathrm{~cm} \times 40 \mathrm{~cm} \times 60 \mathrm{~cm}$ from the tunneling head and send it to the laboratory after being sealed and packed underground. Use a cutting machine to cut the coal sample into a square specimen with a size of $5 \mathrm{~cm} \times 5 \mathrm{~cm} \times 10 \mathrm{~cm}$, and then smooth it with a grinder. The basic parameters of the coal sample are shown in Table 1, and the prepared coal sample is shown in Figure 2.

The author designed a coal cycle-step adsorption/desorption gas experiment. The experimental method is shown in Table 2. The initial charging pressure is $0.4 \mathrm{MPa}$, and the pressure difference is $0.2 \mathrm{MPa}, 0.4 \mathrm{MPa}$, and $0.6 \mathrm{MPa}$. The initial pressure of the desorption experiment is the maximum adsorption equilibrium pressure of the adsorption experiment, and the ambient temperature is maintained at $30^{\circ} \mathrm{C}$ during the experiment.

2.3. Experimental Procedures. The experimental process is shown in Figure 3. The initial gas pressure is the same. After each adsorption equilibrium, the pressure is increased by the same pressure difference until the target pressure is reached. And then the pressure is reduced by the same pressure difference to the minimum pressure.

Step 1. Check the air tightness of the device, install the sample, connect the temperature measurement system and the gas pressure measurement system, turn on the thermostat, adjust the temperature of the thermostat to $30^{\circ} \mathrm{C}$, and start the data logger. 


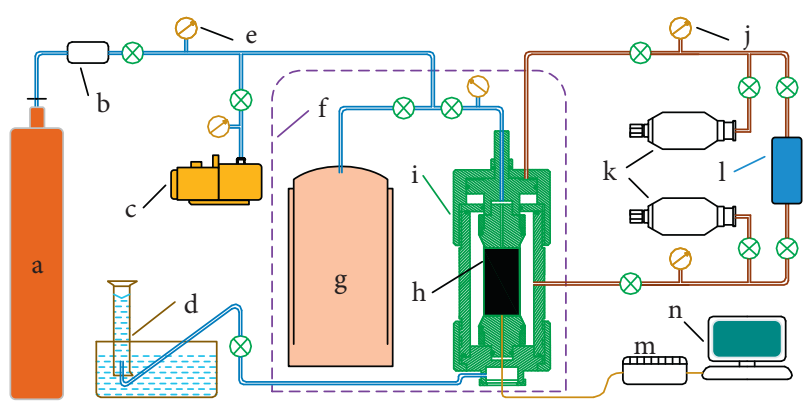

Figure 1: The schematic diagram of gas adsorption and desorption experiment system. a: pressure vessel, b: pressure-reducing valve, c: vacuum, d: gas collection, e: pressure gauge, f: incubator, g: standard tank, h: coal sample, i: adsorption/desorption, j: needle valve, k: pressure regulator, l: hydraulic pump, m: data recorder, and $\mathrm{n}$ : computer.

TABLE 1: Basic parameters of coal sample.

\begin{tabular}{lcccccc}
\hline & \multicolumn{3}{c}{ Industrial } & \multicolumn{2}{c}{ Adsorption } \\
Coal & \multicolumn{3}{c}{ parameters } & \multicolumn{2}{c}{ parameters } & Gas pressure \\
& $M_{\mathrm{ad}}$ & $A_{d}$ & $V_{\mathrm{daf}}$ & $V_{L}$ & $P_{L}(\mathrm{MPa})$ & $(\mathrm{MPa})$ \\
& $(\%)$ & $(\%)$ & $(\%)$ & $\left(\mathrm{m}^{3} / t\right)$ & & \\
\hline Anthracite & 1.19 & 6.31 & 8.25 & 34.76 & 0.6521 & $1.3-2.6$ \\
\hline
\end{tabular}

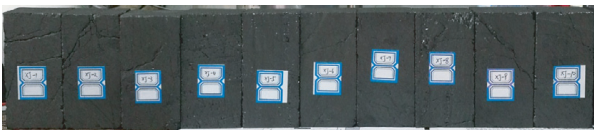

FIgURE 2: Coal sample.

TABle 2: Experimental method.

\begin{tabular}{lc}
$\begin{array}{l}\text { Gas pressure } \\
\text { difference } \\
(\mathrm{MPa})\end{array}$ & Gas pressure loading path $(\mathrm{MPa})$ \\
\hline 0.2 & $0.4 \longrightarrow 0.6 \longrightarrow 0.8 \longrightarrow 1.0 \longrightarrow 1.2 \longrightarrow 1.4 \longrightarrow 1.6$ \\
0.4 & $1.4 \longleftarrow 1.2 \longleftarrow 1.0 \longleftarrow 0.8 \stackrel{\longleftrightarrow}{\longrightarrow} \stackrel{\longleftrightarrow}{\longrightarrow} 0.4$ \\
0.6 & $0.4 \longrightarrow 0.8 \longrightarrow 1.2 \longrightarrow 0.8 \longrightarrow 0.4$ \\
\hline
\end{tabular}

Step 2. Debug the triaxial stress loading system to adjust the axial pressure and confining pressure to predetermined values.

Step 3. Connect the high-pressure gas cylinder to the experimental system.

Step 4 . Turn on the vacuum pump to vacuum degas the gas pressure loading system.

Step 5. Carry out coal adsorption gas experiment. Adjust the pressure reducing valve at the outlet of the high-pressure gas cylinder to the required pressure value so that the pressure of the standard tank reaches the predetermined value. After the gas pressure in the standard tank is stable, the gas in the standard tank is sent to the adsorption/desorption device for continuous adsorption for 12 hours. Record temperature and pressure data.
Step 6. Carry out coal desorption gas experiment. After the adsorption experiment is cycled to the target pressure, the gas pressure in the adsorption/desorption device is reduced with an equal pressure difference, and the desorption is continued for 12 hours. Record temperature and pressure data.

Step 7. Repeat steps 5 and 6 to adjust the gas pressure difference to $0.2 \mathrm{MPa}, 0.4 \mathrm{MPa}$, and $0.6 \mathrm{MPa}$.

\subsection{Results}

2.4.1. Temperature Variation during the Process of Gas Adsorption. Figure 4 shows the comparison of adsorption experiment results under different pressure differences. Under the same pressure difference, the temperature variation of coal sample decreases during the step adsorption process. As the gas pressure difference increases, the temperature variation of coal sample caused by each pressurization gradually increases, and the temperature accumulation decreases. During the adsorption, the temperature change of the coal sample increases with the increase of the pressure difference.

2.4.2. Temperature Variation during the Process of Gas Desorption. Figure 5 shows the comparison of desorption experiment results under different pressure differences. Under the same pressure difference, the temperature variation of coal sample decreases during the desorption. As the gas pressure difference increases, the temperature variation of coal sample caused by each pressure drop gradually increases, and the temperature accumulation decreases. During the desorption, the temperature change of the coal sample increases with the increase of the pressure difference.

\subsubsection{Change Law of Temperature Accumulation of Coal} Sample. To further analyze the relation between the pressure difference and the temperature accumulation of coal sample, the curve in Figure 6 was fitted. The fitting equation is shown in Table 3. It can be seen from the figure that the temperature accumulation first increases with the increase of gas pressure and then tends to be flat, showing a trend of quadratic parabolic change. As the pressure difference increases, the temperature accumulation gradually decreases. When the pressure difference is constant, the temperature accumulation during the adsorption is slightly greater than that during the desorption.

\section{Multifield Coupling Model and Governing Equations}

Coal adsorption/desorption gas is an important part of the mutual coupling relation between coal and gas. The coal adsorption/desorption gas will be accompanied by the absorption and release of heat. Therefore, when scholars establish the thermo-hydro-mechanical coupling model of coal and gas, the adsorption/desorption thermal effect has been studied as an important coupling relation [38-42]. Compared with previous research results, scholars have not 


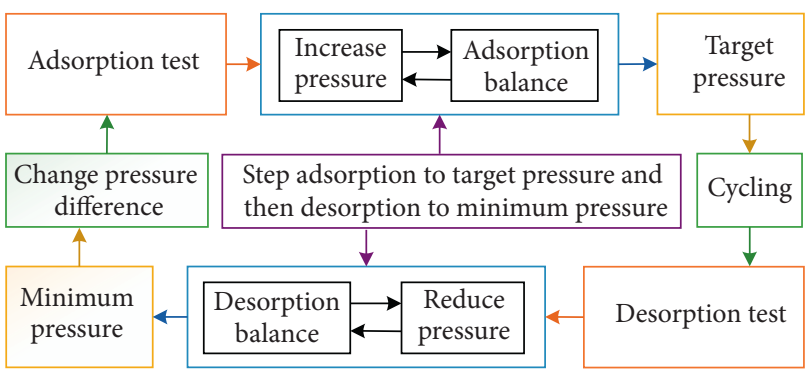

FIGURE 3: Experimental procedure.

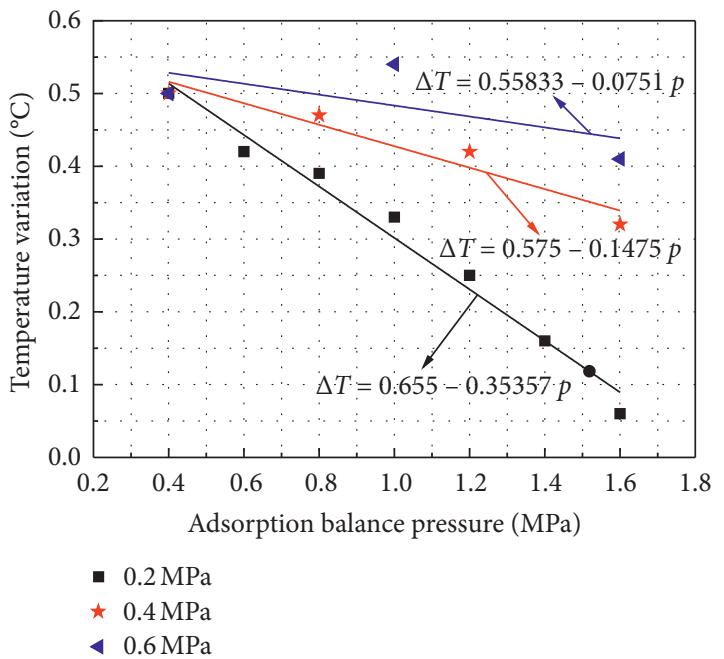

Figure 4: Temperature variation during the gas adsorption.

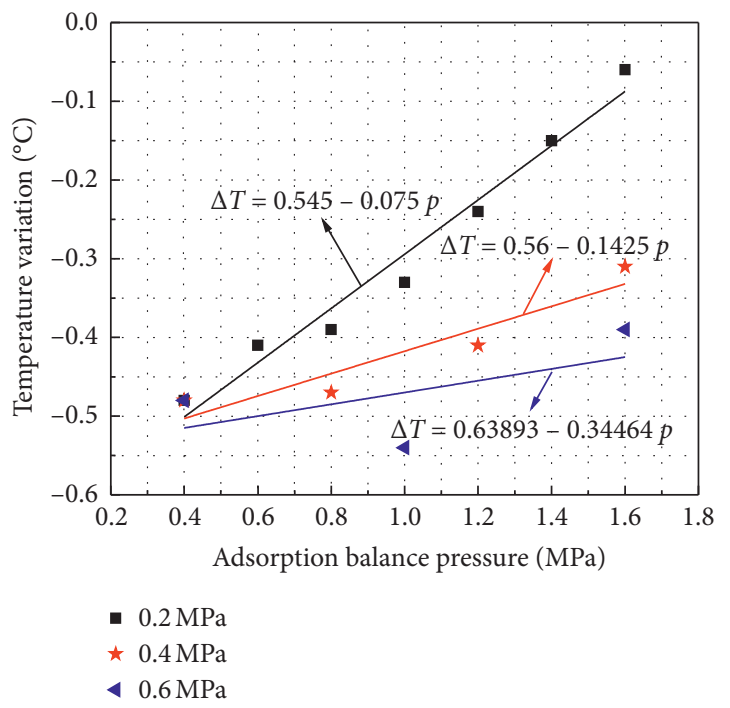

Figure 5: Temperature variation during the gas desorption.

introduced the adsorption/desorption thermal effect into the coupled model from the experimental perspective, and there is no new research progress on the influence of adsorption/ desorption thermal effect on the interaction between coal and gas. Based on the experiments of coal adsorption/

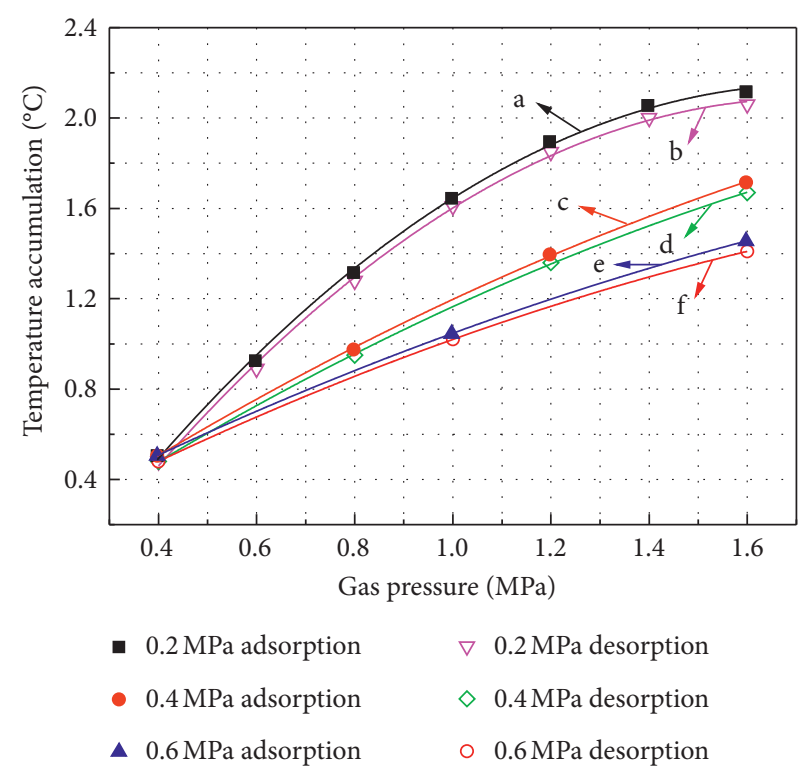

FIgURE 6: Change law of temperature cumulative amount of coal sample.

TABLE 3: Fitting equation of change law of temperature accumulation of coal sample.

\begin{tabular}{lcc}
\hline Curve & Fitting equation & $R^{2}$ \\
\hline A & $T=-0.9256 p^{2}+3.22083 p-0.65857$ & 0.99884 \\
B & $T=-0.93155 p^{2}+3.20774 p-0.67429$ & 0.99868 \\
C & $T=-0.23437 p^{2}+1.48125 p-0.0575$ & 0.99955 \\
D & $T=-0.25 p^{2}+1.495 p-0.08$ & 0.9997 \\
E & $T=-0.1805 p^{2}+1.1527 p+0.0677$ & 0.9999 \\
F & $T=-0.2083 p^{2}+1.19167 p+0.03667$ & 0.9999 \\
\hline
\end{tabular}

desorption gas thermal effects with different pressure differences, this paper explores the influence of adsorption/ desorption thermal effects on the temporal and spatial evolution of outburst precursor information and the mutual coupling relation between coal and gas. Using the theory of continuum mechanics, the laws of static force balance, the mass conservation, and the energy conservation, considering the mutual influence of each physical fields, the thermohydro-mechanical coupling model of coal and gas is derived.

3.1. Model Hypothesis. The thermo-hydro-mechanical coupling of coal and gas is an extremely complex physical process. The establishment of mathematical equations and the convenience of numerical calculations require certain simplified assumptions. This article uses the reasonable assumptions and laws established by the predecessors to propose the following assumptions:

The deformation of the coal is small, and the coal is in the linear elastic deformation stage, which obeys the generalized Hooke law.

The effective stress change of the gassy coal skeleton follows the modified Terzaghi effective stress law.

The seepage law of gas in coal seams conforms to Darcy's law. 
The adsorbed gas in the coal obeys the Langmuir adsorption equilibrium equation, and the free gas obeys the real gas state equation.

The coal is full of single-phase gas.

At the same point, the temperature of gas and coal are equal.

The inertial force and volume force in the process of gas seepage and coal deformation are negligible.

\subsection{Dynamic Porosity and Permeability Models for Gassy Coal.} Compression deformation and adsorption expansion deformation caused by ground stress and gas pressure and thermal expansion deformation caused by temperature changes will cause the coal skeleton to deform. As the buried depth of the coal seam increases, the temperature, ground stress, and gas pressure will change significantly, and coal porosity is also in a process of dynamic change [43-47]. According to the basic assumptions, the porosity of coal can be defined as

$$
\phi=\frac{V_{P}}{V}=\frac{V_{P 0}+\Delta V_{P}}{V_{B 0}+\Delta V}=1-\frac{\left(1-\phi_{0}\right)}{1+e}\left(1+\frac{\Delta V_{S}}{V_{S 0}}\right),
$$

where $V_{S}$ is the coal skeleton volume, $\Delta V_{S}$ is the change of coal skeleton volume, $V_{P}$ is the pore volume, $\Delta V_{P}$ is the change of pore volume, $\phi_{0}$ is the initial porosity, $e$ is the volume strain, $\Delta V$ is the change of total coal volume, and $V$ is the total coal volume.

The volumetric strain increment of coal particles is mainly composed of three parts. $\Delta V_{S} / V_{S 0}$ is the strain increment caused by the pore gas pressure compressing coal particles. $\Delta V_{S F} / V_{S 0}$ is the strain increment caused by the expansion of coal particles during gas adsorption. $\Delta V_{S T} / V_{S 0}$ is the strain increment caused by thermoelastic expansion.

We obtain the porosity equation expressed in terms of effective stress and adsorption thermodynamic parameters:

$$
\phi=1-\frac{1-\phi_{0}}{1+e}\left(1+\alpha_{T} \Delta T-K_{Y} \Delta p+\frac{2 \rho R \Delta T a K_{Y} \ln (1+b p)}{3 V_{m}\left(1-\phi_{0}\right)}\right) .
$$

In addition, it is assumed that the coal permeability and porosity satisfy the following relation [48]:

$$
k=k_{0}\left(\frac{\phi}{\phi_{0}}\right)^{3} \text {. }
$$

Therefore, the permeability equation can be expressed as

$$
k=\frac{k_{0}}{\phi_{0}^{3}}\left[1-\frac{1-\phi_{0}}{1+e}\left(1+\alpha_{T} \Delta T-K_{Y} \Delta p+\frac{2 \rho R \Delta T a K_{Y} \ln (1+b p)}{3 V_{m}\left(1-\phi_{0}\right)}\right)\right]^{3},
$$

where $k_{0}$ is the initial permeability.

3.3. Deformation of Gassy Coal. The continuous solid medium will produce stress and strain under the action of external force. According to the basic assumption, the stress-strain relation can be expressed as $[49,50]$

$$
\varepsilon_{i j}=\frac{1}{2 G} \sigma_{i j}-\left(\frac{1}{6 G}-\frac{1}{9 K}\right) \sigma_{k k} \delta_{i j}
$$

where $\varepsilon_{i j}$ is components of strain tensor, $\sigma_{i j}$ is components of stress tensor, $G$ is shear modulus, and $K$ is bulk modulus.

The temperature change will cause the expansion or contraction of the coal and produce thermal strain. Under the assumption of isotropy, the linear thermal expansion strain can be expressed as

$$
\varepsilon_{T}=\frac{1}{3} \alpha_{T} \Delta T
$$

where $\Delta T$ is temperature change and $\varepsilon_{T}$ is the coefficient of volume thermal expansion of coal.

For coal with free gas, according to the porous linear elastic mechanics and the principle of effective stress, the linear compression strain caused by gas pressure is expressed as

$$
\varepsilon_{p}=-\frac{K_{Y}}{3} \Delta p
$$

where $K_{Y}$ is volume compressibility and $\Delta p$ is gas pressure change.

After coal adsorbs gas, the surface tension of coal particles decreases, and the coal will expand. On the contrary, after coal desorbs gas, the coal will shrink [51]. Therefore, the linear adsorption expansion strain caused by coal particles adsorbing gas is expressed as

$$
\varepsilon_{X}=\frac{2 \rho R a K_{Y} \Delta T}{9 V_{m}} \ln (1+b p),
$$

where $\rho$ is the density of coal, $R$ is the universal gas constant, $a$ is the limit adsorption capacity per unit mass of coal at reference pressure, $b$ is the adsorption equilibrium constant of coal, and $V_{m}$ is the gas molar volume.

Total strain includes strain caused by external force, pore compression strain caused by free gas, adsorption expansion strain, and thermal expansion strain under the coupling action of stress, gas pressure, and temperature, which can be expressed as

$$
\begin{aligned}
\varepsilon_{i j}= & \frac{1}{2 G} \sigma_{i j}-\left(\frac{1}{6 G}-\frac{1}{9 K}\right) \sigma_{k k} \delta_{i j}+\frac{1}{3} \alpha_{T} \Delta T \delta_{i j}-\frac{K_{Y}}{3} \Delta p \delta_{i j} \\
& +\frac{2 \rho R T a K_{Y}}{9 V_{m}} \ln (1+b p) \delta_{i j} .
\end{aligned}
$$

According to the elasticity theory and the revised effective stress formula, the effective stress can be expressed by the balanced differential equation:

$$
\sigma_{i j, j}+\left(\alpha p \delta_{i j}\right)_{, j}+F_{i}=0
$$

Strain component and displacement component accord with Cauchy's equation: 


$$
\varepsilon_{i j}=\frac{1}{2}\left(u_{i, j}+u_{j, i}\right), \quad(i, j=1,2,3) .
$$

According to the strain-stress relation, an equation expressing stress with strain can be derived:

$$
\begin{aligned}
\sigma_{i j}= & 2 G \varepsilon_{i j}+\frac{2 G \nu}{1-2 \nu} \varepsilon_{k k} \delta_{i j}-\frac{(3 \lambda+2 G)}{3} \alpha_{T} \Delta T \delta_{i j} \\
& -\frac{(3 \lambda-2 G)}{3} K_{Y} \Delta p \delta_{i j}-\frac{(3 \lambda+2 G) 2 \rho R T a K_{Y}}{9 V_{m}} \ln (1+b p) \delta_{i j} .
\end{aligned}
$$

Substituting equations (11) and (12) into equation (10), we obtain the improved form of Navier's equation expressed in displacement:

$$
\begin{aligned}
G u_{i, i j}+ & \frac{G \nu}{1-2 \nu} u_{j, j i}-\frac{3 \lambda+2 G}{3} \alpha_{T} \Delta T_{, j}-\frac{3 \lambda-2 G}{3} K_{Y} \Delta p_{, i} \\
& -\frac{(3 \lambda+2 G) 2 \rho R T a K_{Y}}{9 V_{m}} \ln (1+b p)_{, i}+\alpha p_{, i}+F_{, i}=0 .
\end{aligned}
$$

3.4. Gas Flow in Coal. The ideal gas equation only applies to gases at low pressure and high temperature. The compressibility of real gas and ideal gas is different. Therefore, real gas cannot simply be regarded as ideal gas. Gas can be regarded as an incompressible fluid under the conditions of low pressure difference, low flow rate, and small temperature difference. The state equation of gas in coal seam is usually expressed as

$$
\rho_{g}=\frac{M p}{R T Z}
$$

where $\rho_{g}$ is the gas density, $M$ is the gas molecular weight, $T$ is the absolute temperature of the coal seam, $M / R$ is the gas constant of specific gas, and $Z$ is the compression factor.

Assuming that the gas seepage in the coal seam conforms to Darcy's law, and the gravity effect is ignored, the gas seepage velocity can be expressed as

$$
q_{g}=-\frac{k}{\mu} \nabla P
$$

where $q_{g}$ is Darcy's flow rate, $k$ is permeability, $\nabla P$ is the gas pressure gradient, and $\mu$ is the dynamic viscosity coefficient of gas.
Coal is composed of solid framework and pores. The pores are filled with freely diffusing gas. Changes in gas pressure, temperature, or pores will cause gas desorption or adsorption and then cause gas seepage in the cracks. The mass conservation equation of gas seepage in coal can be expressed as

$$
\frac{\partial m}{\partial t}+\nabla \cdot\left(\rho_{g} q_{g}\right)=Q_{s}
$$

where $Q_{s}$ is the source and sink and $m$ is the gas content.

Gas content includes free gas and adsorbed gas [52]. Assuming that free gas is an ideal gas, the gas content of coal can be expressed as

$$
m=\phi \frac{M_{g}}{R T} p+\frac{M_{g} p_{a}}{R T_{a}} \rho_{c} \frac{V_{L} p}{p+P_{L}},
$$

where $\rho_{c}$ is the density of coal, $M_{g}$ is the molar mass of gas, $p_{a}$ is the gas pressure under standard conditions, and $T_{a}$ is the temperature under standard conditions.

The first derivative of the gas content equation can be expressed as

$$
\frac{\partial m}{\partial t}=\frac{M_{g} p}{R T} \frac{\partial \phi}{\partial t}+\frac{M_{g} \phi}{R T} \frac{\partial p}{\partial t}-\rho_{c} \frac{M_{g} p_{a}}{R T_{a}} \frac{V_{L} P_{L}}{\left(p+P_{L}\right)^{2}} \frac{\partial p}{\partial t}-\frac{M_{g} p \phi}{R T^{2}} \frac{\partial T}{\partial t} .
$$

Substituting equations (14), (15), and (18) into equation (16), we have

$$
p \frac{\partial \phi}{\partial t}+\left(\phi-\frac{\rho_{c} p_{a} V_{L} P_{L}}{\left(p+P_{L}\right)^{2}}\right) \frac{\partial p}{\partial t}-\frac{p}{T} \phi \frac{\partial T}{\partial t}-\nabla \cdot\left(\frac{k}{\mu} p \nabla P\right)=0 .
$$

The derivative of porosity with respect to time is expressed as

$$
\begin{aligned}
\frac{\partial \phi}{\partial t}= & \frac{1-\phi_{0}}{(1+e)^{2}}\left(\alpha_{T} \Delta T-K_{Y} \Delta p+\frac{2 \rho R T a K_{Y} \ln (1+b p)}{3 V_{m}\left(1-\phi_{0}\right)}\right) \frac{\partial e}{\partial t} \\
& -\frac{1-\phi_{0}}{1+e}\left(\alpha_{T}+\frac{2 \rho R a K_{Y} \ln (1+b p)}{3 V_{m}\left(1-\phi_{0}\right)}\right) \frac{\partial T}{\partial t} \\
& -\frac{\left(1-\phi_{0}\right) K_{Y}}{1+e}\left(\frac{2 \rho R T a b}{3 V_{m}\left(1-\phi_{0}\right)(1+b p)}\right) \frac{\partial p}{\partial t} .
\end{aligned}
$$

Substituting equation (20) into equation (19), we have

$$
\begin{array}{r}
\frac{p\left(1-\phi_{0}\right)}{(1+e)^{2}}\left(\alpha_{T} \Delta T-K_{Y} \Delta p+\frac{2 \rho R T a K_{Y} \ln (1+b p)}{3 V_{m}\left(1-\phi_{0}\right)}\right) \frac{\partial e}{\partial t}-\frac{p\left(1-\phi_{0}\right)}{1+e}\left(\alpha_{T}+\frac{2 \rho R a K_{Y} \ln (1+b p)}{3 V_{m}\left(1-\phi_{0}\right)}+\frac{\phi}{T}\right) \frac{\partial T}{\partial t} \\
+\left(\phi-\frac{\rho_{c} p_{a} V_{L} P_{L}}{\left(p+P_{L}\right)^{2}}-\frac{p\left(1-\phi_{0}\right) K_{Y}}{1+e}\left(\frac{2 \rho R T a b}{3 V_{m}\left(1-\phi_{0}\right)(1+b p)}-1\right)\right) \frac{\partial p}{\partial t}-\nabla \cdot\left(\frac{k}{\mu} p \nabla P\right)=0 .
\end{array}
$$


To simplify equation (21), we define some parameters as $C_{1}=C_{3} \frac{\partial e}{\partial t}+C_{4} \frac{\partial T}{\partial t}$

$C_{2}=\left(\phi-\frac{\rho_{c} p_{a} V_{L} P_{L}}{\left(p+P_{L}\right)^{2}}-\frac{p\left(1-\phi_{0}\right) K_{Y}}{1+e}\left(\frac{2 \rho R T a b}{3 V_{m}\left(1-\phi_{0}\right)(1+b p)}-1\right)\right)$,

$C_{3}=\frac{p\left(1-\phi_{0}\right)}{(1+e)^{2}}\left(\alpha_{T} \Delta T-K_{Y} \Delta p+\frac{2 \rho R T a K_{Y} \ln (1+b p)}{3 V_{m}\left(1-\phi_{0}\right)}\right)$,

$C_{4}=-\frac{p\left(1-\phi_{0}\right)}{1+e}\left(\alpha_{T}+\frac{2 \rho R a K_{Y} \ln (1+b p)}{3 V_{m}\left(1-\phi_{0}\right)}+\frac{\phi}{T}\right)$.

Therefore, the equation (21) is simplified to

$$
C_{1}+C_{2} \frac{\partial p}{\partial t}-\nabla \cdot\left(\frac{k}{\mu} p \nabla P\right)=0
$$

Equation (23) is the governing equation of gas seepage in coal seams.

3.5. Heat Transfer Equation. If the heat filtering effect is ignored, but the heat convection effect is considered, the constitutive equation of heat conduction can be expressed by Fourier's law as

$$
\begin{aligned}
& q_{T}=-\lambda_{M} \nabla T+\rho_{g} C_{g} q_{g} T, \\
& \lambda_{M}=(1-\phi) \lambda_{s}+\phi \lambda_{g},
\end{aligned}
$$

where $q_{T}$ is heat flow through fluid and solid media, $\lambda_{M}$ is thermal conductivity of coal, $\lambda_{s}$ is thermal conductivity of coal particles, $\lambda_{g}$ is thermal conductivity of gas, and $C_{s}$ is constant volume heat capacity of gas.

Assuming that the heat balance between the solid and the fluid is maintained, the heat balance equation on the characteristic unit body can be expressed as [53]

$$
\begin{gathered}
\frac{\partial\left((\rho C)_{M} T\right)}{\partial t}+T K_{g} \alpha_{g} \nabla \cdot q_{g}+T K \alpha_{T} \frac{\partial e}{\partial t}=-\nabla \cdot q_{T}+Q_{h t}, \\
(\rho C)_{M}=\phi\left(\rho_{g} C_{g}\right)+(1-\phi)\left(\rho_{s} C_{s}\right),
\end{gathered}
$$

where $(\rho C)_{M}$ is the overall heat capacity of the porous medium, $\rho_{s}$ is density of coal skeleton, $C_{s}$ is constant volume heat capacity of coal matrix, $K_{g}$ is bulk modulus of gas, $\alpha_{g}$ is the volumetric thermal expansion coefficient of gas under constant pore pressure and stress, and $Q_{h t}$ is the heat caused by coal adsorption/desorption gas.

The first term on the left-hand side of equation (26) is the change rate of internal energy per unit volume caused by temperature change. The second term represents the heat dissipation due to the thermal expansion of the fluid. The third term represents the heat dissipation due to the thermal expansion of the coal matrix. The right-hand side represents the overall heat flow of fluid and solid medium [34].

Substituting equations (24), (25), and (27) into equation (26), according to the assumption of small deformation and the law of conservation of mass, it is further simplified as

$$
(\rho C)_{M} \frac{\partial(T)}{\partial t}-T K_{g} \alpha_{g} \nabla \cdot\left(\frac{k}{\mu} \nabla P\right)+T K \alpha_{T} \frac{\partial e}{\partial t}=\lambda_{M} \nabla^{2} T+\frac{\rho_{g a} p T_{a} C_{g}}{p_{a} T} \nabla T \cdot\left(\frac{k}{\mu} \nabla P\right)+Q_{h t} .
$$

Equations (13), (23), and (28) constitute an equations' set describing the interaction between coal and gas, which considers the coupling among the stress field, seepage field, and temperature field. The solid mechanics module, PDE module, and solid heat transfer module of COMSOL Multiphysics can be used to solve the coupled model.

3.6. Cross-Coupling Relations. Figure 7 shows the crosscoupling relation between coal deformation, gas seepage, and temperature changes. The stress changes the porosity and permeability of the coal and then affects the seepage process of free gas. The change of free gas pressure causes gas adsorption or desorption and causes the coal to expand or contract. The increase of temperature promotes the desorption of adsorbed gas and accelerates the seepage rate of free gas. The adsorption and desorption of gas is accompanied by the absorption and release of heat. Heat convection and internal energy dissipation in the process of gas seepage speed up the heat transfer. The temperature change produces thermal strain, which causes the coal to expand or contract. The deformation of coal is also accompanied by the storage or release of deformation energy [54, 55].
The temperature change during coal and gas outburst includes two aspects: coal temperature rise in process of coal rupture and coal adsorption. Gas desorption and gas expansion lead to lower coal temperature. According to the assumption of linear elasticity, the temperature change during coal and gas outburst can be expressed as

$$
\Delta T=\Delta T_{1}+\Delta T_{2}+\Delta T_{3}
$$

where $\Delta T_{1}$ is temperature drop caused by gas expansion, $\Delta T_{2}$ is temperature drop caused by gas desorption, and $\Delta T_{3}$ is temperature rise caused by gas adsorption.

According to the experimental results of coal adsorption/desorption gas thermal effect under different pressure differences, the energy change caused by coal adsorption/ desorption gas can be expressed as

$$
Q_{h}=C_{m} \rho_{c}\left(\Delta T_{2}+\Delta T_{3}\right)
$$

As the increase of temperature, the amount of adsorbed gas in the coal seam gradually decreases. According to the experiment results, the relation between adsorption constant and temperature is fitted. 


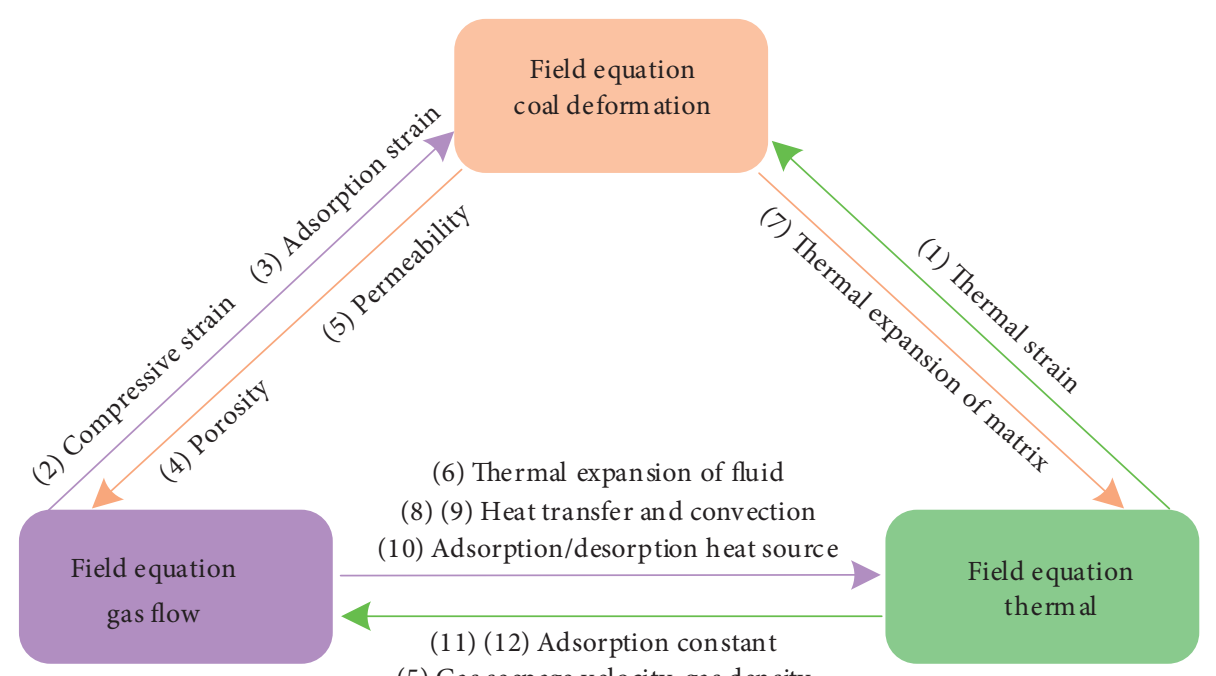

(5) Gas seepage velocity, gas den sity

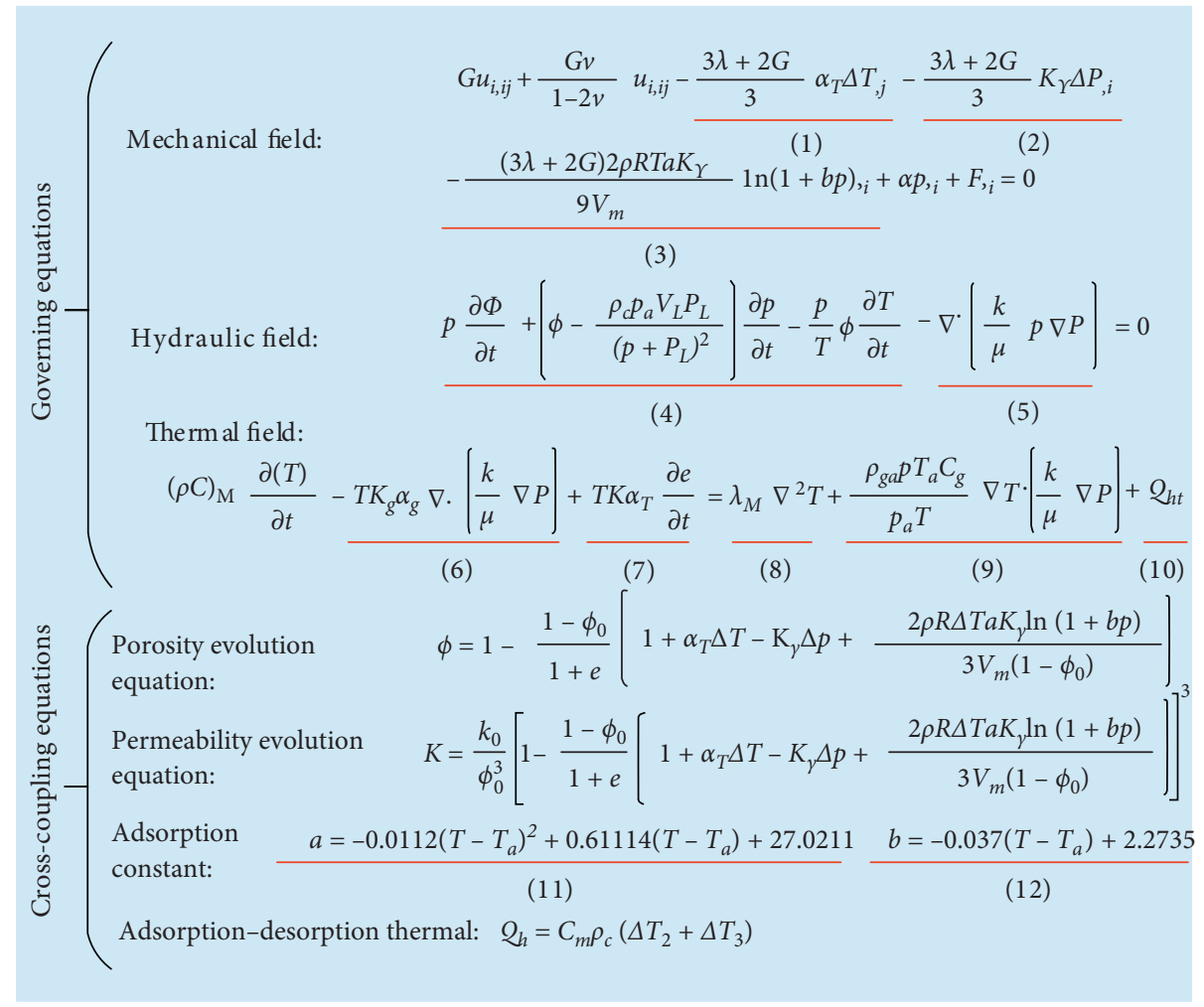

Figure 7: Cross-coupling relations and the basic THM governing equations.

$$
\begin{aligned}
& a=-0.0112\left(T-T_{a}\right)^{2}+0.61114\left(T-T_{a}\right)+27.0211, \\
& b=-0.037\left(T-T_{a}\right)+2.2735 .
\end{aligned}
$$

\section{Model Validation}

To verify the rationality of the thermo-hydro-mechanical coupling model established in this paper, based on the physical simulation experiment of coal and gas outburst carried out by scholars, the numerical simulation study on the change law of gas pressure and temperature of coal in the aeration stage was carried out [37]. The geometric model is shown in Figure 8. The model has a width of $570 \mathrm{~mm}$ and a height of $365 \mathrm{~mm}$. Boundary conditions of stress field: the upper boundary applies a vertical force of $4 \mathrm{MPa}$; the right boundary applies a horizontal force of $2.4 \mathrm{MPa}$. The left and lower boundaries are roller supports. Boundary conditions of the seepage field: the upper, left and right boundaries are zero flux, the lower boundary has a constant gas pressure of $1 \mathrm{MPa}$, and the initial gas pressure is $0.1 \mathrm{MPa}$. Boundary conditions of the temperature field: the temperature around the model is constant at $293 \mathrm{~K}$, and the initial temperature is also $293 \mathrm{~K}$. Point $\mathrm{A}$ is the gas pressure monitoring point, and point $\mathrm{B}$ is the temperature monitoring point. 


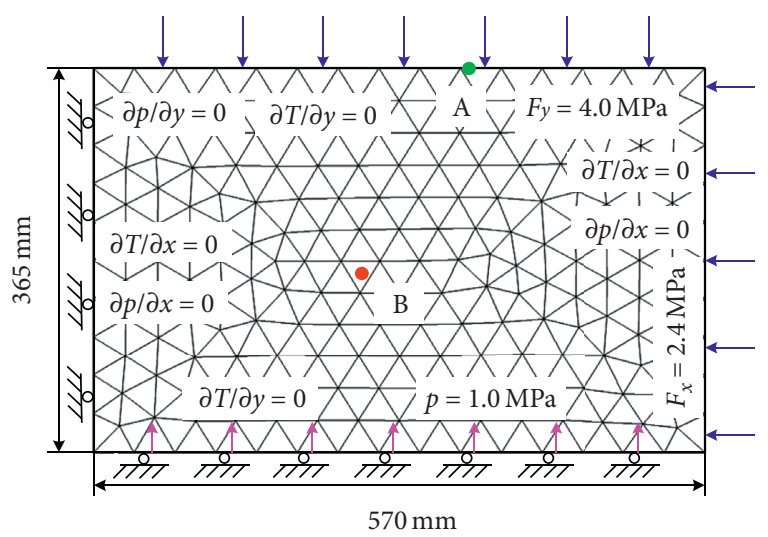

FIGURE 8: Geometric model for inflation simulation.

The numerical calculation results and experiment results are shown in Figure 9. The experiment results showed that the gas pressure at point A remains unchanged for the first 8 seconds in the initial inflation stage, and then the gas pressure increases rapidly. After inflation to $110 \mathrm{~s}$, the gas pressure reaches $1 \mathrm{MPa}$. The temperature at point $\mathrm{B}$ increases rapidly after the start of inflation. After inflating to $100 \mathrm{~s}$, the temperature change rate decreases. The maximum temperature measured in the experiment is $295.5 \mathrm{~K}$. Numerical calculation results under different pressure differences show that the gas pressure at point $\mathrm{A}$ remains unchanged for the first 10 seconds in the initial inflation stage, and then the gas pressure increases rapidly. After inflation to $110 \mathrm{~s}$, the gas pressure reaches $1 \mathrm{MPa}$. The gas pressure changes under different pressure differences are the same, and the change variation is small. After the inflation starts, the temperature at point B increases rapidly. With the increase of the pressure difference, the maximum temperature is $297.3 \mathrm{~K}, 296.0 \mathrm{~K}, 295.5 \mathrm{~K}$. The temperature change decreases as the pressure difference increases. The calculated result with a pressure difference of $0.6 \mathrm{MPa}$ is close to the experimental result. The temperature change rate measured in the experiment after the start of inflation is greater than the numerical calculation result. According to the analysis, under the assumption of small linear elastic deformation, the energy released by coal deformation is small and the frictional heat of coal particles is ignored in numerical calculation. The difference in temperature changes under different pressure differences will be analyzed below.

Comparing the experimental results and the numerical calculation results, it is found that the numerical solution and the experimental solution are in good agreement. In summary, the thermo-hydro-mechanical coupling model of coal and gas can be used to simulate the evolution of precursor information during the preparation stage of coal and gas outburst.

\section{Numerical Simulation and Discussion}

Numerical calculations are carried out based on the thermohydro-mechanical coupling model of coal and gas, which considers the adsorption/desorption thermal effect. Comparing the calculation results with or without the adsorption/desorption thermal effect, the influence of the adsorption/desorption thermal effect on the evolution of coal and gas outburst precursor information is analyzed, and the mechanism of the adsorption/desorption thermal effect on the mutual coupling relation between coal and gas is studied.

5.1. Geometric Model. The geometric model is shown in Figure 10. Model includes coal seam, coal seam roof, and coal seam floor. Designed working face and gas drainage borehole in the coal seam: the size of the roof and floor of the coal seam is $43 \mathrm{~m} \times 25 \mathrm{~m} \times 2 \mathrm{~m}$. The size of the coal seam is $43 \mathrm{~m} \times 25 \mathrm{~m} \times 3 \mathrm{~m}$. The width of the working surface is $5 \mathrm{~m}$. The working face surface is $5 \mathrm{~m}$ from the left boundary. The gas drainage borehole is $5 \mathrm{~m}$ away from the coal wall of the working face, the borehole diameter is $0.094 \mathrm{~m}$, and the borehole depth is $20 \mathrm{~m}$. The working face and the outside of the coal seam are free spaces, which can be regarded as exposed coal walls. Stress field boundary conditions: the upper boundary of the coal seam roof is subjected to a vertical uniform load of 9.8 $\mathrm{MPa}$, the working face and the coal wall are free boundaries, the other boundaries around the model are supported by rollers, and the lower boundary of the coal seam floor is a fixed displacement. Boundary conditions of the seepage field: there is no gas flow between the coal seam and the rock, the initial gas pressure of the coal seam is $1.3 \mathrm{MPa}$, the gas pressure of the coal wall is $0.1 \mathrm{MPa}$, the suction pressure of the borehole is $14 \mathrm{kPa}$, and other boundaries have no flow. Boundary conditions of temperature field: there is no heat transfer between coal seam and rock layer, the initial temperature of coal seam is $292.4 \mathrm{~K}$, the temperature of coal wall is $291.15 \mathrm{~K}$, and other boundaries are zero flux. Along the advancing direction of the working face, a monitoring line is arranged in the coal seam. The parameters required for numerical calculation are shown in Table 4.

\subsection{Simulation Results and Discussion}

5.2.1. Evolution Law of Precursor Information without Adsorption/Desorption Thermal Effect. Figure 11 shows the distribution characteristics of the stress, gas pressure, and temperature of the coal in front of the working face and near the coal wall in the roadway without the adsorption/desorption thermal effect. The stress on the bottom of the working face is the smallest, and the coal walls on both sides and roof are stress concentration areas. As shown in Figure 12, the stress concentration area in the coal in front of the working face is $0-28.41 \mathrm{~m}$, the gas discharge zone width is $10 \mathrm{~m}$, the maximum volumetric strain in the stress concentration area is -0.00628 , and the maximum coal temperature is $292.41 \mathrm{~K}$. The coal temperature rises by $0.01 \mathrm{~K}$, and the minimum permeability is $8.83 \times 10^{-19} \mathrm{~m}^{2}$. The increase in coal temperature without the adsorption/desorption thermal effect is caused by deformation energy. Under the assumption of small linear elastic deformation, the volumetric strain is small, and the coal deformation generates less heat. The location where the volumetric strain is 


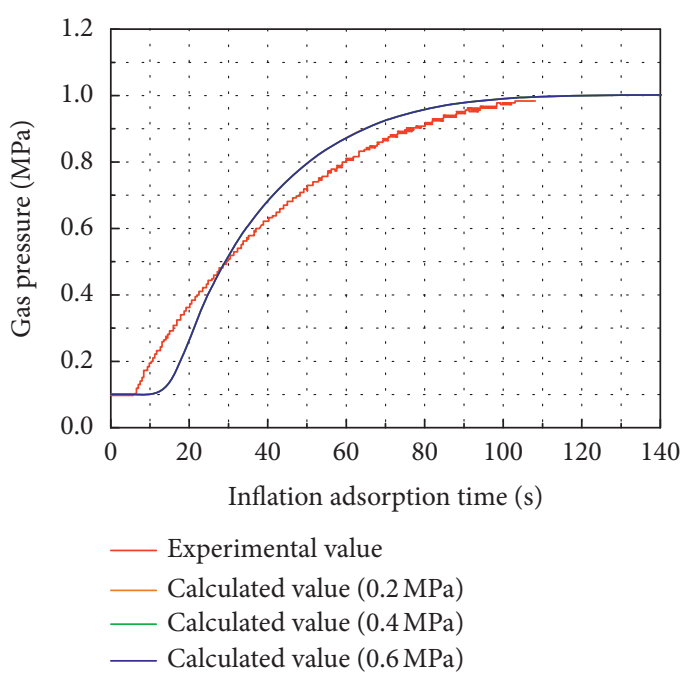

(a)

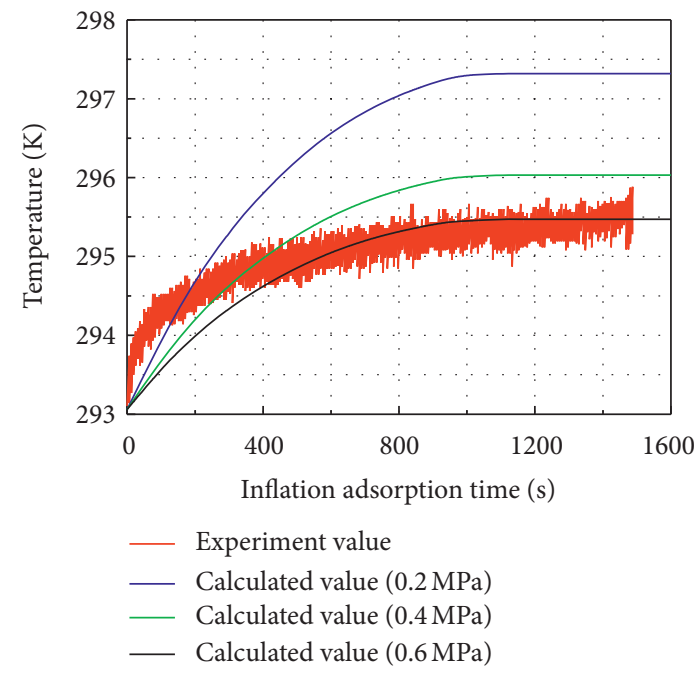

(b)

FIgURE 9: (a) Gas pressure change and (b) temperature change curve during inflation.

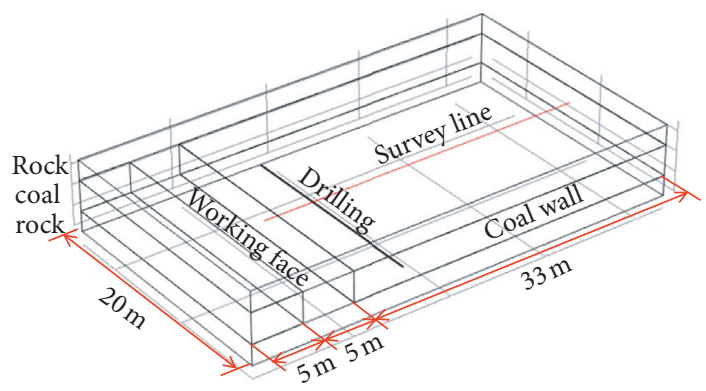

(a)

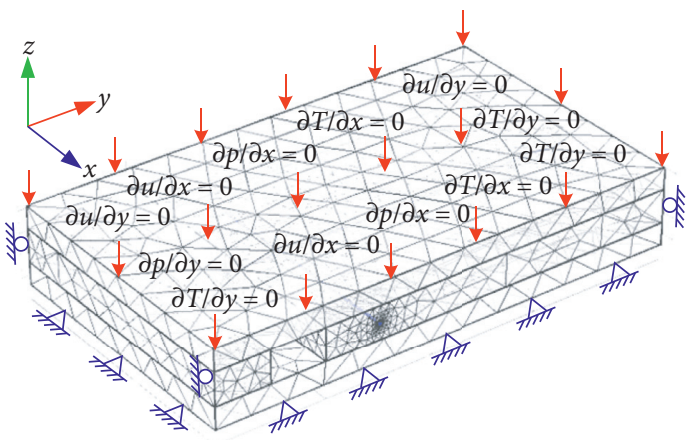

(b)

FIGURE 10: Geometry and boundary conditions for the coupled mechanical deformation, gas flow and heat conduction process in coal seam, where gas flow and heat conduction apply only in the coal seam.

the largest has the smallest permeability. Coal deformation is the result of the combined action of ground stress, adsorption expansion stress, and pore compression stress.

5.2.2. Evolution Law of Precursor Information with Adsorption/Desorption Thermal Effect. Figure 13 shows the distribution characteristics of the stress, gas pressure, and temperature of the coal in front of the working face and near the coal wall in the roadway considering the adsorption/ desorption thermal effect under different pressure difference. As shown in Figure 12, when the pressure difference is $0.2 \mathrm{MPa}$, the stress concentration area in the coal in front of the working face is $0-32.05 \mathrm{~m}$, the width of the gas discharge zone is $13 \mathrm{~m}$, the maximum volume strain is -0.00637 , and the maximum coal temperature is $296.05 \mathrm{~K}$, the coal temperature rises by $3.65 \mathrm{~K}$, and the minimum coal permeability is $8.41 \times 10^{-19} \mathrm{~m}^{2}$; when the pressure difference is $0.4 \mathrm{MPa}$, the stress concentration area in the coal in front of the working face is $0-29.47 \mathrm{~m}$, the width of the gas discharge zone is $12 \mathrm{~m}$, the maximum volume strain is -0.00632 , and the maximum coal temperature is $294.39 \mathrm{~K}$, the coal temperature rises by $1.99 \mathrm{~K}$, and the minimum coal permeability is $8.60 \times 10^{-19} \mathrm{~m}^{2}$; when the pressure difference is $0.6 \mathrm{MPa}$, the stress concentration area in the coal in front of the working face is $0-28.52 \mathrm{~m}$, the width of the gas discharge zone is $11 \mathrm{~m}$, the maximum volume strain is -0.00630 , and the maximum coal temperature is $293.24 \mathrm{~K}$, the coal temperature rises by $0.85 \mathrm{~K}$, and the minimum coal permeability is $8.73 \times 10^{-19} \mathrm{~m}^{2}$. The gas pressure difference increased from $0.2 \mathrm{MPa}$ to $0.4 \mathrm{MPa}$, the maximum difference in gas pressure was $10023 \mathrm{~Pa}$, the increase in coal temperature decreased by $1.66 \mathrm{~K}$, and the permeability increased by $1.94 \times 10^{-20} \mathrm{~m}^{2}$. The gas pressure difference increased from $0.4 \mathrm{MPa}$ to $0.6 \mathrm{MPa}$, the maximum difference in gas pressure was $5002 \mathrm{~Pa}$, the increase in coal temperature decreased by $1.14 \mathrm{~K}$, and the permeability increased by $1.26 \times 10^{-20} \mathrm{~m}^{2}$. As the increase of the gas pressure difference, the width of the gas discharge zone decreases, and the temperature elevated amount and change rate of the coal temperature gradually 
TABLE 4: The parameters used for gas migration in coal seam.

\begin{tabular}{|c|c|c|c|}
\hline Variable & Parameter & Value & Unit \\
\hline$E$ & Young's modulus of coal & $2.56 \times 10^{3}$ & $\mathrm{MPa}$ \\
\hline$v$ & Poisson's ratio of coal & 0.12 & \\
\hline$\rho_{c}$ & Density of coal & 1400 & $\mathrm{~kg} \cdot \mathrm{m}^{-3}$ \\
\hline$R$ & Universal gas constant & 8.3143 & $\mathrm{~J} \cdot \mathrm{mol}^{-1} \mathrm{~K}^{-1}$ \\
\hline$V_{m}$ & Gas molar volume & $22.4 \times 10^{-3}$ & $\mathrm{~m}^{3} \cdot \mathrm{mol}^{-1}$ \\
\hline$\phi_{0}^{m}$ & Initial porosity of coal & 0.0436 & \\
\hline$k_{0}$ & Initial permeability of coal & $1.77 \times 10^{-18}$ & $\mathrm{M}^{2}$ \\
\hline$T_{0}$ & Initial temperature & 292.4 & $\mathrm{~K}$ \\
\hline$p_{0}$ & Initial gas pressure of coal & 1.3 & $\mathrm{MPa}$ \\
\hline$\mu$ & Methane dynamic viscosity & $1.087 \times 10^{-5}$ & $\mathrm{~Pa} \cdot \mathrm{s}$ \\
\hline$\rho_{q a}$ & Density of gas at standard condition & 0.717 & $\mathrm{~kg} \cdot \mathrm{m}^{-3}$ \\
\hline$p_{a}$ & Pressure at standard condition & 0.101325 & $\mathrm{MPa}$ \\
\hline$V_{L}$ & Langmuir's volume constant & 0.03476 & $\mathrm{~m}^{3} \cdot \mathrm{kg}^{-1}$ \\
\hline$P_{L}$ & Langmuir's pressure constant & 0.6521 & $\mathrm{MPa}$ \\
\hline$T_{a}$ & Temperature at standard condition & 273 & $\mathrm{~K}$ \\
\hline$\alpha_{T}$ & Volumetric thermal expansion of the solid matrix coefficient & 0.000116 & $\mathrm{~K}^{-1}$ \\
\hline$\lambda_{s}$ & Thermal conductivity of coal particles & 0.443 & $\mathrm{~J} \cdot \mathrm{m}^{-1} \cdot \mathrm{s}^{-1} \mathrm{~K}^{-1}$ \\
\hline$C_{g}^{s}$ & Specific heat capacity of gas & 2.16 & $\mathrm{~kJ} \cdot \mathrm{kg}^{-1} \mathrm{~K}^{-1}$ \\
\hline$C_{s}^{9}$ & Specific heat capacity of coal & 1.26 & $\mathrm{~kJ} \cdot \mathrm{kg}^{-1} \mathrm{~K}^{-1}$ \\
\hline
\end{tabular}

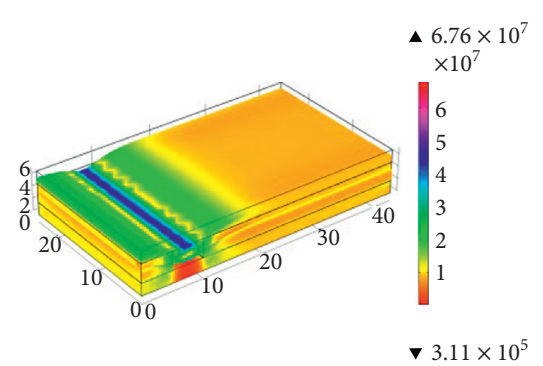

(a)

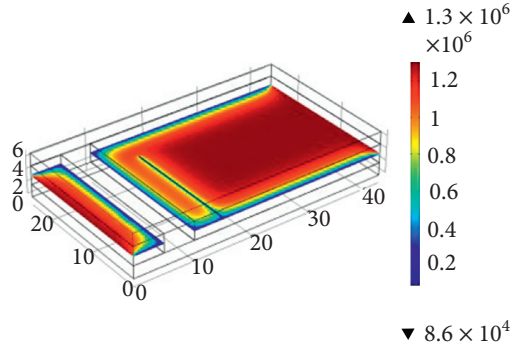

(b)

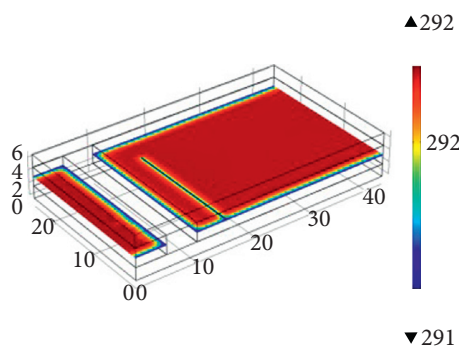

(c)

FIGURE 11: Stress, gas pressure, and temperature distribution without adsorption/desorption thermal heat. (a) Stress. (b) Gas pressure. (c) Temperature.

decrease. The deformation energy and the adsorption/desorption thermal effect cause the coal temperature to change. The higher the temperature, the greater the volumetric strain and the lower the permeability. The extreme point of volumetric strain and permeability overlaps with the position where the extreme point of temperature appears. Within the range of $0-10 \mathrm{~m}$ in front of the working face, near the extreme point, temperature has a more obvious effect on volumetric strain and permeability. Within $10 \mathrm{~m}$ from the working front, the variation range of volumetric strain is mainly controlled by ground stress, and the influence of temperature is relatively small.

\subsubsection{Effect of Adsorption/Desorption Thermal Effect on the} Mutual Coupling Relation between Coal and Gas. Figure 12 shows the influence of the adsorption/desorption thermal effect on the evolution of precursor information in the preparation stage of coal and gas outburst. Comparing the research results with or without the adsorption/desorption thermal effect, it is found that the adsorption/desorption thermal effect have obvious effects on coal gas pressure, temperature, volumetric strain, permeability, and other parameters. Comparing the evolution law of gas pressure, temperature, volumetric strain, and permeability of coal in front of the working face without the adsorption/desorption thermal effect, the temperature change caused by the adsorption/desorption thermal effect is larger, and the coal temperature increase is $3.64 \mathrm{~K}, 1.98 \mathrm{~K}$, and $0.84 \mathrm{~K}$; the adsorption/desorption thermal effect has little effect on coal gas pressure, and the maximum difference of gas pressure is $20285 \mathrm{~Pa}, 10596 \mathrm{~Pa}$, and $5600 \mathrm{~Pa}$; the adsorption/desorption thermal effect has a great influence on the volumetric strain of coal, and the increase in volumetric strain of coal is $9 \times 10^{-5}$, $4 \times 10^{-5}$, and $2 \times 10^{-5}$; the adsorption/desorption thermal effect has an obvious influence on permeability, and the decrease in permeability is $4.21 \times 10^{-20} \mathrm{~m}^{2}, 2.27 \times 10^{-20} \mathrm{~m}^{2}$, and $1.01 \times 10^{-20} \mathrm{~m}^{2}$. The location where the gas pressure difference is the largest is about $1.5 \mathrm{~m}$ in front of the working face, where the slope of the gas pressure curve is the largest, and the temperature change is the largest. Therefore, the effect of thermal expansion strain caused by adsorption/desorption thermal effect on coal permeability cannot be ignored. The thermal expansion strain caused by the temperature change in 


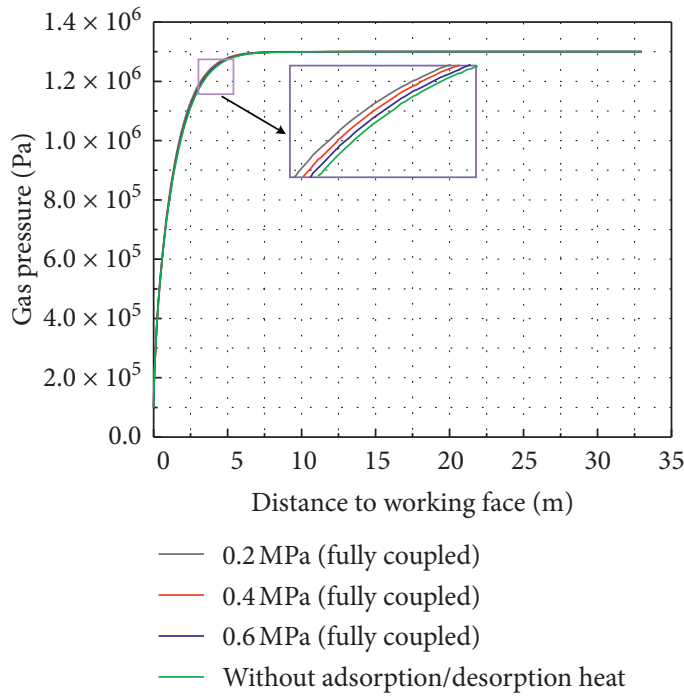

(a)

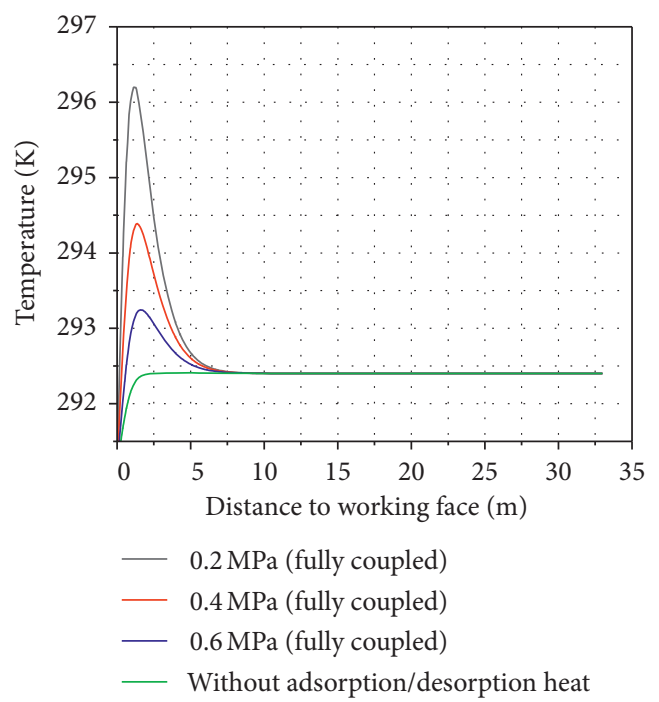

(c)

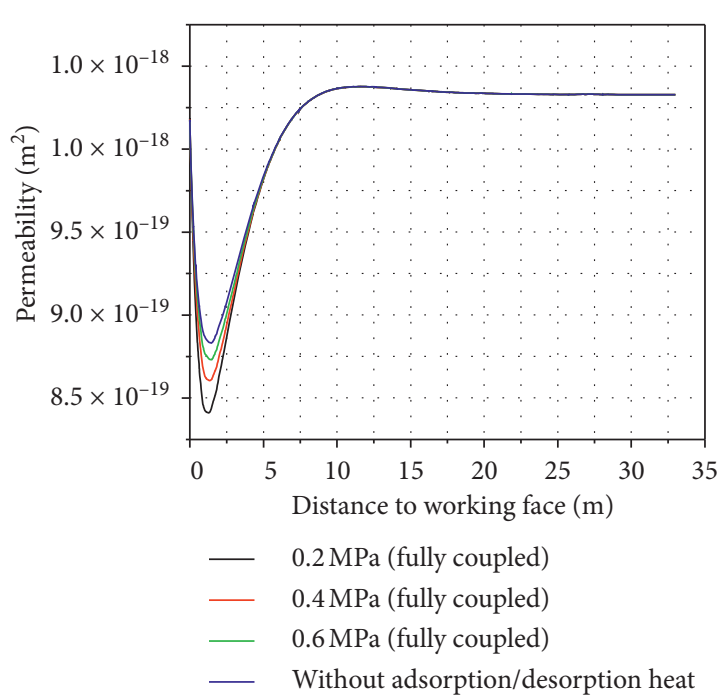

(b)

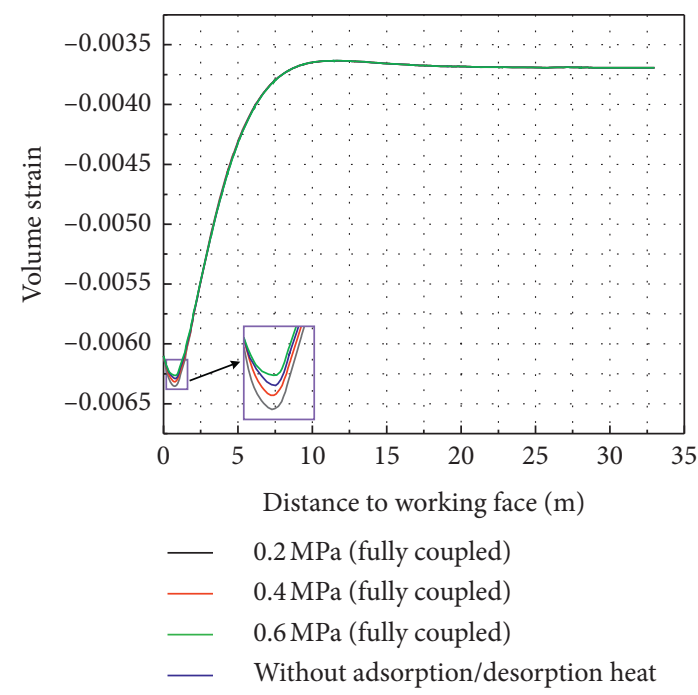

(d)

FIGURE 12: Gas pressure, permeability, temperature, and volume strain distribution along the monitoring line with or without adsorption/ desorption heat. (a) Gas pressure. (b) Temperature. (c) Volume strain. (d) Permeability.

the preparation stage of coal and gas outburst leads to the decrease of coal permeability and increases the outburst risk.

Figure 14 shows the change law of gas pressure, permeability, and temperature in the coal and gas drainage volume around the borehole with or without the adsorption/ desorption thermal effect. Figure 14(b) shows that the temperature change is obvious within the influence range of the borehole. The temperature change near the borehole wall is large, and the farther away from the borehole, the smaller the temperature change. As shown in Figure 14(d), the maximum gas drainage volume is $964 \mathrm{~m}^{3}$ without the adsorption/desorption thermal effect. As the pressure difference increases, the gas drainage volume increases gradually, and the maximum gas drainage volume of a single hole is $888 \mathrm{~m}^{3}, 915 \mathrm{~m}^{3}$, and $940 \mathrm{~m}^{3}$. Comparing the calculation results without the adsorption/desorption thermal effect, the maximum gas drainage volume of a single hole is reduced by $76 \mathrm{~m}^{3}, 49 \mathrm{~m}^{3}$, and $24 \mathrm{~m}^{3}$. Assuming that 1000 boreholes are arranged in the working face, the maximum gas drainage volume of a single hole is reduced by $7.6 \times 10^{4} \mathrm{~m}^{3}$, $4.9 \times 10^{4} \mathrm{~m}^{3}$, and $2.4 \times 10^{4} \mathrm{~m}^{3}$. With the increase of gas pressure difference, the volumetric strain of coal decreases and the permeability increases, which is beneficial to the desorption of gas. On the contrary, the coal temperature decreases with the increase of gas pressure difference, and the decrease of temperature is not conducive to the desorption and flow of gas. Analyzing the change law of gas drainage volume in boreholes, it can be seen that the effect of thermal expansion strain caused by adsorption/desorption thermal effect on gas seepage is greater than the effect of temperature change on gas seepage. In summary, the adsorption/desorption thermal effect not only causes the coal 


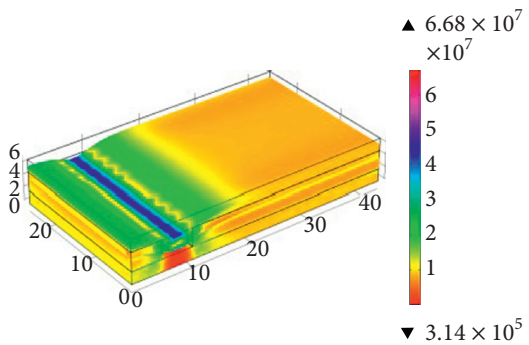

(a)

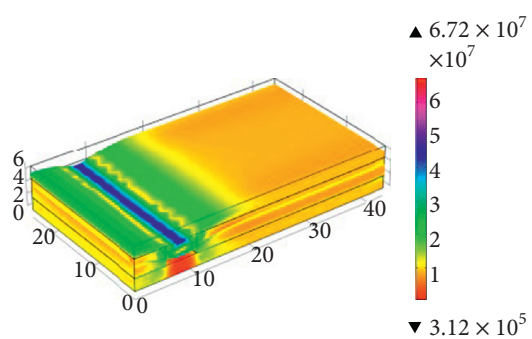

(d)

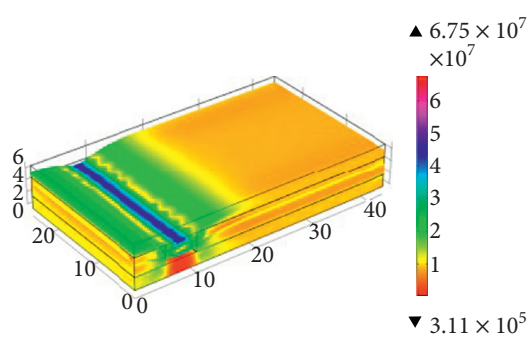

(g)

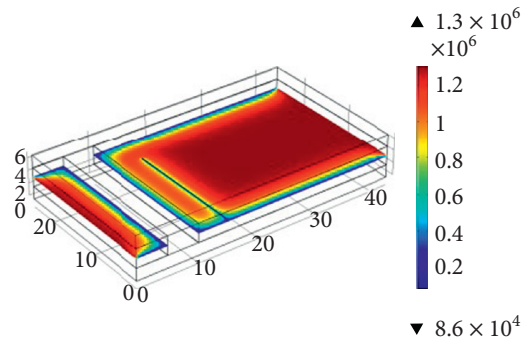

(b)

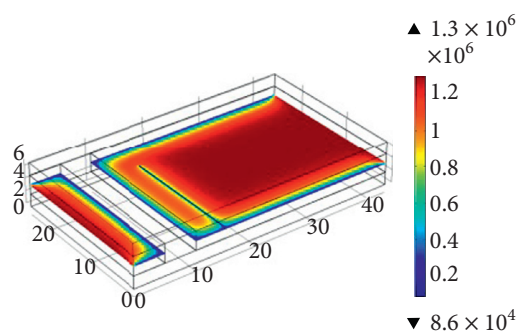

(e)

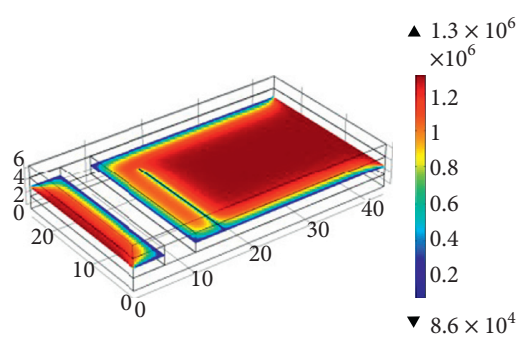

(h)

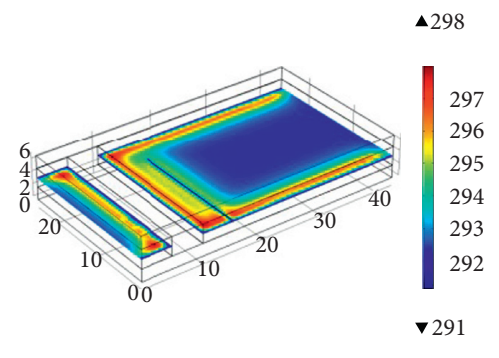

(c)

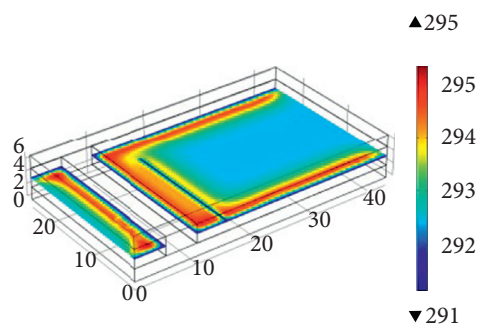

(f)

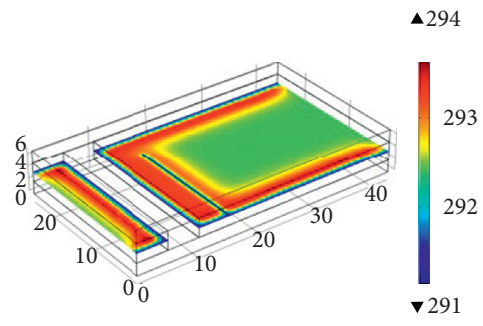

(i)

FIGURE 13: Stress, gas pressure, and temperature distribution at different pressure differences with adsorption/desorption heat. (a) $0.2 \mathrm{MPa}$ stress. (b) $0.2 \mathrm{MPa}$ gas pressure. (c) $0.2 \mathrm{MPa}$ temperature. (d) $0.4 \mathrm{MPa}$ stress. (e) $0.4 \mathrm{MPa}$ gas pressure. (f) $0.4 \mathrm{MPa}$ temperature. (g) $0.6 \mathrm{MPa}$ stress. (h) 0.6 MPa gas pressure. (i) $0.6 \mathrm{MPa}$ temperature

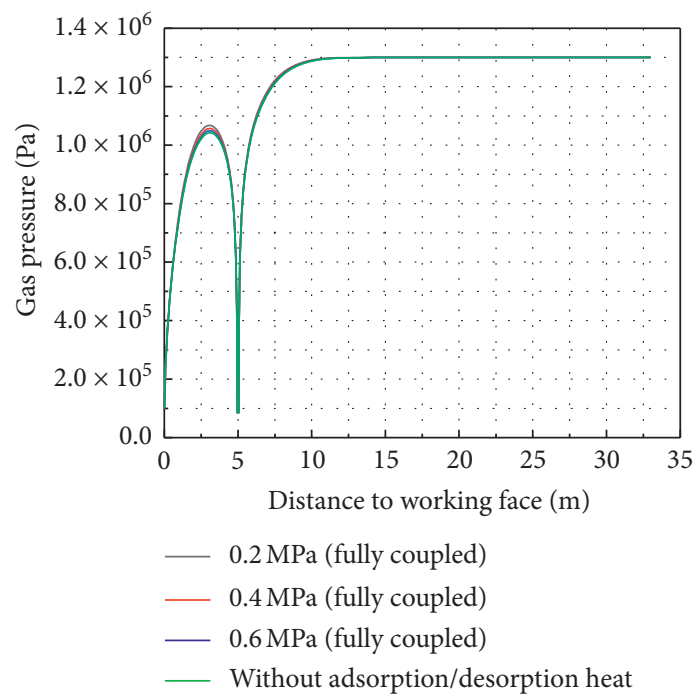

(a)

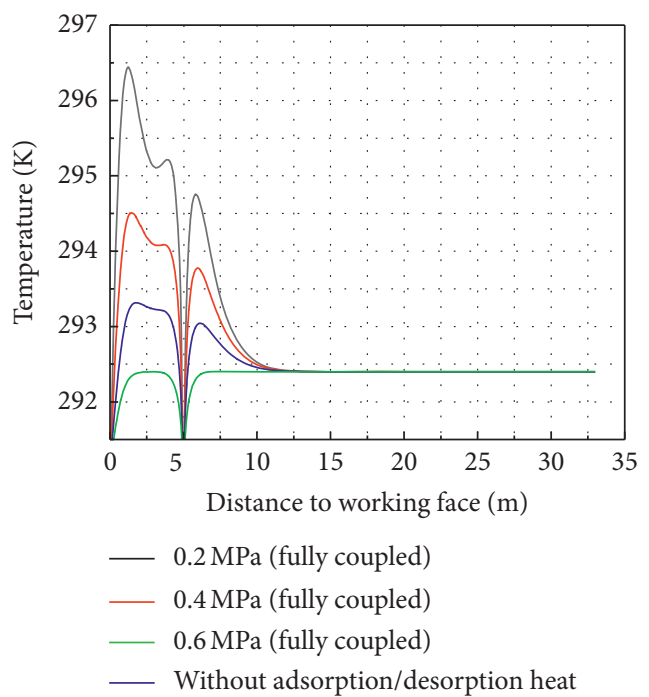

(b)

FIGURE 14: Continued. 


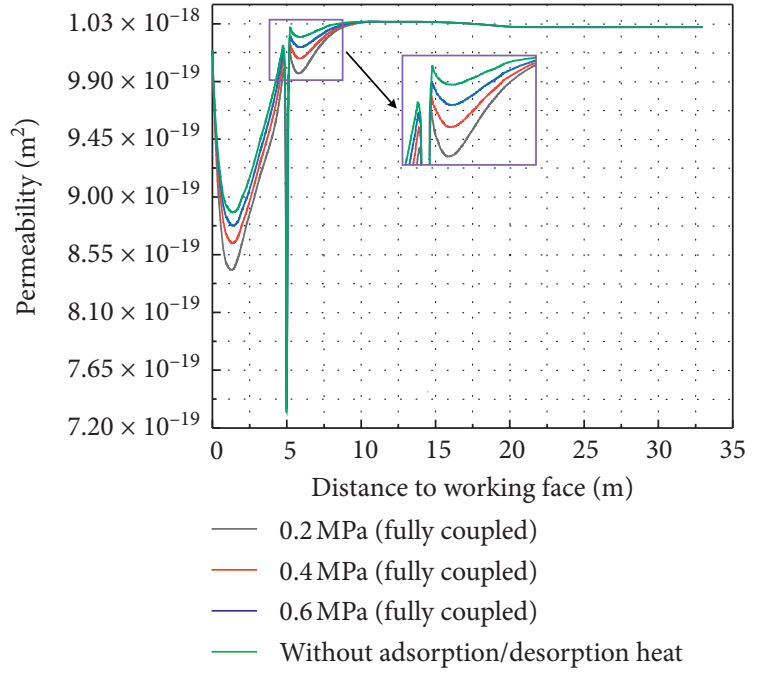

(c)

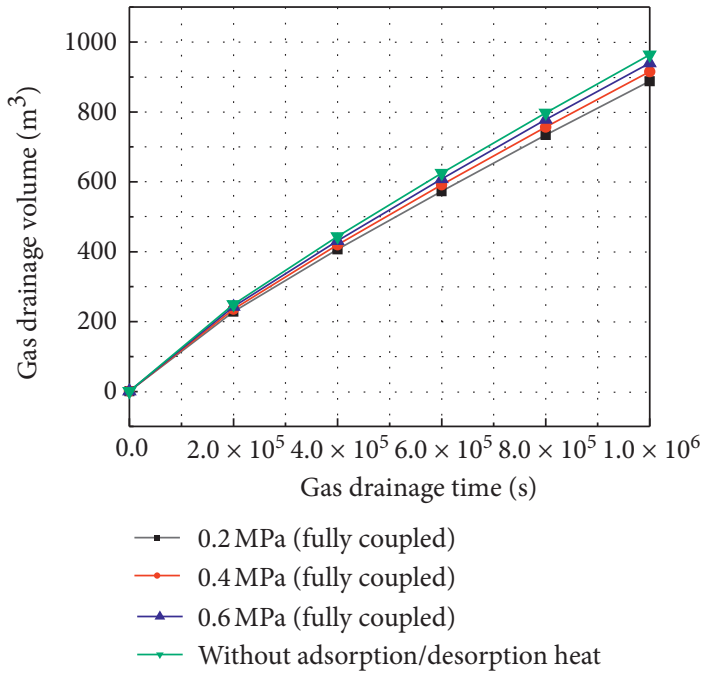

(d)

FIGURE 14: Gas pressure, temperature, permeability distribution in the coal near the borehole, and gas extraction volume with or without adsorption/desorption heat. (a) Gas pressure. (b) Temperature. (c) Permeability. (d) Gas drainage volume.

temperature change, but also has a greater effect on coal seam gas seepage.

\section{Conclusions}

Based on the coal adsorption/desorption gas thermal effect experiment, this paper established a thermo-hydro-mechanical coupling model of coal and gas considering the adsorption/desorption thermal effect by analyzing the mutual coupling relation among the stress, gas, and temperature. The evolution of precursor information in the preparation stage of coal and gas outburst is simulated with or without the adsorption/desorption thermal effect, and the effect of the adsorption/desorption thermal effect on the mutual coupling relation between coal and gas is discussed. The main conclusions are as follows:

(1) The relation between gas pressure difference and coal temperature variation is linear. Under the same pressure difference, the increasing range of the temperature variation of the coal sample gradually decreases with the increase of the gas pressure difference. The gas pressure difference has a quadratic parabolic relation with the temperature accumulation of coal sample. When the pressure difference is constant, the decreasing range of temperature accumulation decreases gradually with the increase of gas pressure difference. As the pressure difference increases, the temperature variation gradually increases, but the temperature accumulation gradually decreases.

(2) Based on the interaction between coal and gas, the mechanical model reflecting the dynamic evolution of porosity and permeability, gas adsorption-desorption-diffusion, and energy accumulation and dissipation was established with the adsorption/desorption thermal effect.
(3) As the gas pressure difference increases, the changes in coal temperature and gas pressure gradually decrease, the thermal expansion strain caused by the adsorption/desorption thermal effect decreases, and the permeability gradually increases. The evolution law of coal temperature depends on the rate and variation of gas pressure.

(4) Considering the adsorption/desorption thermal effect, the volume strain, temperature, and permeability have significant changes. The gas drainage volume increases significantly with the pressure difference increases. The thermal expansion strain caused by adsorption/desorption thermal effect has a greater effect on gas seepage than temperature change.

\section{Data Availability}

All the data used to support the findings of this study are available from the corresponding author upon request.

\section{Conflicts of Interest}

The authors declare that there are no conflicts of interest regarding the publication of this paper.

\section{Acknowledgments}

This research was funded by the National Natural Science Foundation of China (Grant nos. 51874166 and 51774165); National Key Research and Development Program of China (Grant no. 2016YFC0801404); Discipline Innovation Team of Liaoning Technical University (LNTU20TD-11); National Natural Science Foundation of China Youth Fund (Grant no. 52004118); and Youth Project of Education Department of Liaoning Province (LJ2019QL005 and LJ2020QNL009). 


\section{References}

[1] A. J. Hargraves, "Instantaneous outbursts of coal and gas-a review: hargraves," International Journal of Rock Mechanics \& Mining sciences \& Geomechanics Abstract, vol. 20, no. 5, p. 151, 1983.

[2] N. Skoczylas, "Coal seam methane pressure as a parameter determining the level of the outburst risk-laboratory and in situ research/ciśnienie złożowe jako parametr określający stan zagrożenia wyrzutami metanu I skał-badania laboratoryjne I kopalniane," Archives of Mining Sciences, vol. 57, no. 4, pp. 861-869, 2012.

[3] D. Li, J. Zhang, Y. Sun, and G. Li, "Evaluation of rockburst hazard in deep coalmines with large protective island coal pillars," Natural Resources Research, vol. 5, 2020.

[4] J. Zhang, F. Jiang, S. Zhu, and L. Zhang, "Width design for gobs and isolated coal pillars based on overall burst-instability prevention in coal mines," Journal of Rock Mechanics and Geotechnical Engineering, vol. 8, no. 4, pp. 551-558, 2016.

[5] J. Zhang, F. Jiang, J. Yang, W. Bai, and L. Zhang, "Rockburst mechanism in soft coal seam within deep coal mines," International Journal of Mining Science and Technology, vol. 27, no. 3, pp. 551-556, 2017.

[6] S. Chattaraj, D. Mohanty, T. Kumar, and G. Halder, "Thermodynamics, kinetics and modeling of sorption behaviour of coalbed methane - a review," Journal of Unconventional Oil and Gas Resources, vol. 16, pp. 14-33, 2016.

[7] W. S. Han, G. A. Stillman, M. Lu, C. Lu, B. J. McPherson, and E. Park, "Evaluation of potential nonisothermal processes and heat transport during $\mathrm{CO}_{2}$ sequestration," Journal of Geophysical Research, vol. 115, no. B7, 2010.

[8] J. Sobczyk, "The influence of sorption processes on gas stresses leading to the coal and gas outburst in the laboratory conditions," Fuel, vol. 90, no. 3, pp. 1018-1023, 2011.

[9] J. Sobczyk, "A comparison of the influence of adsorbed gases on gas stresses leading to coal and gas outburst," Fuel, vol. 115, pp. 288-294, 2014.

[10] Y. Sun, G. Li, J. Zhang, and D. Qian, "Stability control for the rheological roadway by a novel high-efficiency jet grouting technique in deep underground coal mines," Sustainability, vol. 11, no. 22, p. 6494, 2019.

[11] J. Zhang, D. Li, and Y. Wang, "Predicting tunnel squeezing using a hybrid classifier ensemble with incomplete data," Bulletin of Engineering Geology and the Environment, vol. 11, 2020.

[12] R. J. Williams and J. J. Weissman, "Gas emission and outburst assessment in mixed $\mathrm{CO}_{2}$ and $\mathrm{CH}_{4}$ environments," University of New South Wales, vol. 1, pp. 1-13, 1995.

[13] J. Zhang and Y. Wang, "An ensemble method to improve prediction of earthquake-induced soil liquefaction: a multidataset study," Neural Computing and Applications, vol. 2, 2020.

[14] J. Rutqvist, Y.-S. Wu, C.-F. Tsang, and G. Bodvarsson, “A modeling approach for analysis of coupled multiphase fluid flow, heat transfer, and deformation in fractured porous rock," International Journal of Rock Mechanics and Mining Sciences, vol. 39, no. 4, pp. 429-442, 2002.

[15] S. Xue, Y. Wang, J. Xie, and G. Wang, "A coupled approach to simulate initiation of outbursts of coal and gas-model development," International Journal of Coal Geology, vol. 86, no. 2-3, pp. 222-230, 2011.

[16] G. Hu, H. Wang, X. Fan, Z. Yuan, and S. Hong, "Mathematical model of coalbed gas flow with klinkenberg effects in multi- physical fields and its analytic solution," Transport in Porous Media, vol. 76, no. 3, p. 407, 2009.

[17] K. Wu, Z. Shao, S. Qin, and Z. Chu, "A critical review on the performance of yielding supports in squeezing tunnels," Tunnelling and Underground Space Technology, vol. 109, no. 1, 2021.

[18] D. Johns and B. G. Neal, Thermal Stress Analyses, Elsevier, Berlin, Germany, 1965.

[19] H. Basarir, Y. Sun, and G. Li, "Gateway stability analysis by global-local modeling approach," International Journal of Rock Mechanics and Mining Science, vol. 113, pp. 31-40, 2018.

[20] Z. Pan and L. D. Connell, "A theoretical model for gas adsorption-induced coal swelling," International Journal of Coal Geology, vol. 69, no. 4, pp. 243-252, 2007.

[21] J. Jagiełło, M. Lasoń, and N. Adam, "Thermodynamic description of the process of gas liberation from a coal bed," Fuel, vol. 71, no. 4, pp. 431-435, 1992.

[22] K. A. Rahman, A. Chakraborty, B. B. Saha, and K. C. Ng, "On thermodynamics of methane+carbonaceous materials adsorption," International Journal of Heat and Mass Transfer, vol. 55, no. 4, pp. 565-573, 2012.

[23] K. A. Rahman, W. S. Loh, and K. C. Ng, "Heat of adsorption and adsorbed phase specific heat capacity of methane/activated carbon system," Procedia Engineering, vol. 56, pp. 118-125, 2013

[24] Z. Liu, Z. Feng, Q. Zhang, D. Zhao, and H. Guo, "Heat and deformation effects of coal during adsorption and desorption of carbon dioxide," Journal of Natural Gas Science and Engineering, vol. 25, pp. 242-252, 2015.

[25] C. A. Tang, L. G. Tham, P. K. K. Lee, T. H. Yang, and L. C. Li, "Coupled analysis of flow, stress and damage (FSD) in rock failure," International Journal of Rock Mechanics and Mining Sciences, vol. 39, no. 4, pp. 477-489, 2002.

[26] Y. Sun, G. Li, and J. Zhang, "Investigation on jet grouting support strategy for controlling time-dependent deformation in the roadway," Energy Science and Engineering, vol. 10, pp. 1-8, 2020.

[27] J. Liu, Z. Chen, and D. Elsworth, "Interactions of multiple processes during CBM extraction: a critical review," International Journal of Coal Geology, vol. 87, no. 3-4, pp. 175-189, 2011.

[28] K. Wu and Z. Shao, "Visco-elastic analysis on the effect of flexible layer on mechanical behavior of tunnels," International Journal of Applied Mechanics, vol. 11, no. 3, 2019.

[29] H. Wang, Z. Liu, L. Yuan, S. Wang, S. Wei, and D. Zhang, "Experimental test and particle mechanical analysis of gas adsorption-induced coal rock degradation," Powder Technology, vol. 362, pp. 75-83, 2020.

[30] Y. Zheng, Q. Li, G. Zhang, Y. Zhao, and X. Li, "Study on the coupling evolution of air and temperature field in coal mine goafs based on the similarity simulation experiments," Fuel, vol. 283, 2021.

[31] P. Thararoop, Z. T. Karpyn, and T. Ertekin, "Development of a multi-mechanistic, dual-porosity, dual-permeability, numerical flow model for coalbed methane reservoirs," Journal of Natural Gas Science and Engineering, vol. 8, pp. 121-131, 2012.

[32] T. Teng, Y. Zhao, F. Gao, J. G. Wang, and W. Wang, "A fully coupled thermo-hydro-mechanical model for heat and gas transfer in thermal stimulation enhanced coal seam gas recovery," International Journal of Heat and Mass Transfer, vol. 125, pp. 866-875, 2018.

[33] W. Zhu, C. Wei, J. Liu, H. Qu, and D. Elsworth, "A model of coal-gas interaction under variable temperatures," 
International Journal of Coal Geology, vol. 86, no. 2-3, pp. 213-221, 2011.

[34] Y. Zhou, R. K. N. D. Rajapakse, and J. Graham, “A coupled thermoporoelastic model with thermo-osmosis and thermalfiltration," International Journal of Solids and Structures, vol. 35, no. 34-35, pp. 4659-4683, 1998.

[35] M. Fall, O. Nasir, and T. S. Nguyen, "A coupled hydro-mechanical model for simulation of gas migration in host sedimentary rocks for nuclear waste repositories," Engineering Geology, vol. 176, pp. 24-44, 2014.

[36] F.-h. An, Y.-p. Cheng, L. Wang, and W. Li, "A numerical model for outburst including the effect of adsorbed gas on coal deformation and mechanical properties," Computers and Geotechnics, vol. 54, pp. 222-231, 2013.

[37] Y. Tao, Study on the Gassy Coal THM Coupling Model and Coal and Gas Outburst Simulation, Chongqing University, Chongqing, China, 2015.

[38] Y. Sun, G. Li, N. Zhang, Q. Chang, and J. Zhang, "Development of ensemble learning models to evaluate the strength of coal-grout materials," International Journal of Mining Science and Technology, vol. 5, 2020.

[39] J. Zhang, Y. Wang, Y. Sun, and G. Li, "Strength of ensemble learning in multiclass classification of rockburst intensity," International Journal for Numerical and Analytical Methods in Geomechanics, vol. 5, pp. 1-21, 2020.

[40] Y. Chen, T. Chu, X. Chen, and P. Chen, "Coupling of stress and gas pressure in dual porosity medium during coal seam mining," Powder Technology, vol. 367, pp. 390-398, 2020.

[41] J. Zhang, Y. Sun, G. Li, Y. Wang, and J. Li, "Machine-learningassisted shear strength prediction of reinforced concrete beams with and without stirrups," Engineering With Computers, vol. 5, 2020.

[42] X. Liu, C. Wu, G. Wei et al., "Adsorption deformation characteristics of coal and coupling with permeability during gas injection," Journal of Petroleum Science and Engineering, vol. 195, 2020.

[43] Y. Sun, J. Zhang, G. Li, Y. Wang, J. Sun, and C. Jiang, "Optimized neural network using beetle antennae search for predicting the unconfined compressive strength of jet grouting coalcretes," International Journal for Numerical and Analytical Methods in Geomechanics, vol. 23, pp. 1-13, 2019.

[44] Y. Sun, J. Zhang, G. Li et al., "Determination of Young's modulus of jet grouted coalcretes using an intelligent model," Engineering Geology, vol. 252, pp. 43-53, 2019.

[45] X. Cui and R. M. Bustin, "Volumetric strain associated with methane desorption and its impact on coalbed gas production from deep coal seams," AAPG Bulletin, vol. 89, no. 9, pp. 1181-1202, 2005.

[46] Y. Sun, G. Li, H. Basarir, A. Karrech, and M. R. Azadi, "Laboratory evaluation of shear strength properties for cement-based grouted coal mass," Arabian Journal of Geoences, vol. 12, no. 22, p. 690, 2019.

[47] Y. Sun, G. Li, J. Zhang, and D. Qian, "Experimental and numerical investigation on a novel support system for controlling roadway deformation in underground coal mines," Energy Science and Engineering, vol. 10, pp. 1-11, 2019.

[48] I. Palmer and J. Mansoori, "How permeability depends on stress and pore pressure in coalbeds: a new model," SPE Reservoir Evaluation \& Engineering, vol. 1, no. 6, pp. 539-544, 1998.

[49] M. Wierzbicki, "Changes in stress and strain of the briquette during provoking and initiation of the rock and gas outburst in the laboratory conditions," Transactions of the Strata Mechanics Research Institute, vol. 4, 2003.
[50] K. Wu, Z. Shao, S. Qin, N. Zhao, and H. Hu, "Analytical-based assessment of effect of highly deformable elements on tunnel lining within viscoelastic rocks," International Journal of Applied Mechanics, vol. 12, no. 3, 2020.

[51] H. Zhang, J. Liu, and D. Elsworth, "How sorption-induced matrix deformation affects gas flow in coal seams: a new FE model," International Journal of Rock Mechanics and Mining Sciences, vol. 45, no. 8, pp. 1226-1236, 2008.

[52] A. Saghafi, M. Faiz, and D. Roberts, "CO2 storage and gas diffusivity properties of coals from Sydney Basin, Australia," International Journal of Coal Geology, vol. 70, no. 1-3, pp. 240-254, 2007.

[53] F. Tong, L. Jing, and R. W. Zimmerman, "A fully coupled thermo-hydro-mechanical model for simulating multiphase flow, deformation and heat transfer in buffer material and rock masses," International Journal of Rock Mechanics and Mining Sciences, vol. 47, no. 2, pp. 205-217, 2010.

[54] T. Liu, Multifield Coupling Processes during Gas Drainage in Deep Fractured Coal Seam and its Engineering Response, China University of Mining and Technology, Xuzhou China, 2019.

[55] K. Wu, Z. Shao, and S. Qin, "An analytical design method for ductile support structures in squeezing tunnels," Archives of Civil and Mechanical Engineering, vol. 20, 2020. 